\title{
Colaba-Alibag magnetic observatory and Nanabhoy Moos: the influence of one over the other
}

\author{
P. B. Gawali, M. G. Doiphode, and R. N. Nimje \\ Indian Institute of Geomagnetism, Plot No. 5, Sector 18, Kalamboli Highway, New Panvel, \\ Navi Mumbai - 410 218, India \\ Correspondence to: P. B. Gawali (prachoo99@yahoo.co.in)
}

Received: 5 November 2014 - Revised: 1 August 2015 - Accepted: 24 August 2015 - Published: 16 September 2015

\begin{abstract}
The first permanent magnetic observatories in colonial India were established by the East India Company and under the Göttingen Magnetic Union. One of the world's longest running observatories was set up at Colaba (Bombay) in 1841, which was shifted to Alibag in 1904 to avoid electric traction effects on magnetic recordings. The observatory is located at the northwestern tip of Maharashtra, India, on the Arabian Sea. The magnetic data at Colaba were collected through eye-observation instruments from 1841 to 1872 and by photographic (magnetograph) instruments from 1872 to 1905, which reveal seasonal and other periodic effects on geomagnetic elements. Seasonal influence can be deciphered on the $H$ minimum, but not on the maximum; the disturbances in March and April were opposite to those in December and January. $D$ was maximum in 1880 $\left(57^{\prime} \mathrm{E}\right)$ and minimum in $1904\left(10^{\prime} \mathrm{E}\right)$. The data from 1882 to 1905 revealed that $H$ annual inequality was influenced by 5.5-year periodicity, $D$ by 13.5 days from 1888 to 1905 , and $I$ and $Z$ by 11 -year periodicity from 1894 to 1905 and 1873 to 1905 , respectively. Secular variation of $Z$ was parallel to that of $I$. $Z$ exhibited an increasing trend from 1868 (12874 nT) to 1905 (15083 nT). The plan and location of Colaba-Alibag as well as the instruments used are discussed. The initial Colaba magnetic data containing "magnetic disturbances" was harnessed to identify the "disturbing point" on Earth. Nanabhoy Moos, the first Indian director, presciently hinted at a solar origin for magnetic disturbances, revealed the dependence of magnetic elements on the sunspot cycle, unraveled disturbance daily variation, and tried to understand the association, if any, between geomagnetic, seismological and meteorological phenomena. The two giant volumes published in 1910 attest to Moos' seminal work and his inventiveness in organizing and analyzing long series data. He also had a major role in moving Colaba magnetic observatory to Alibag. Thus, the observatory and Moos had a synergestic relationship influencing each other. The long data series has as much historical significance as scientific, which can bring out short- as well as long-term trends in geomagnetic data.
\end{abstract}

\section{Introduction}

Geomagnetic research has undergone a series of seminal shifts to understand nature in its primal form. The sighting of certain metals attracting each other opened up new avenues for the savants to view and analyze the world. The directional property, learned by the Greeks, was also understood by the Chinese (Crichton, 1932), who harnessed it in many forms. The transfer of this knowledge to the Europeans (Smith, 1992), probably through Arabs, changed the way this "attractive" "directional" property was used. It opened up new vistas through the efforts of Robert Norman (dip;
Crichton, 1939), William Gilbert (Earth is a magnet; Gilbert, 1958), Henry Gellibrand (declination changes; Malin and Bullard, 1981), Edmond Halley (declination change map; Bauer, 1896, 1913), Hans Christian Oersted (effect of electricity on magnetism; Shamos, 1959), Andre Marie Ampere (magnetism can be produced without iron; Williams, 1989), Michael Faraday (magnetism can produce electricity; Baggot, 1991), James Clerk Maxwell (mathematical formulation securing the relation between electricity and magnetism; Maxwell, 1873) and the trio of Alexander von Humboldt (established magnetic observatories all over the globe; Cawood, 
1979), Carl Friedrich Gauss and Wilhelm Weber (designed instruments and formulated a mathematical method to represent the global magnetic field; Gauss, 1832; Gauss and Weber, 1839).

In 1834 Humboldt, Gauss and Weber founded the Göttingen Magnetic Union (GMU; Gauss, 1839), which profoundly impacted India. The Renaissance changed the cultural and social landscape of the European world, who, armed with the latest discoveries and inventions, subjugated many countries of the world, including India. The seeds of geomagnetism were sown in India by the British colonialists. The East India Company set up a few meteorological observatories at Madras (Chennai), Bombay (Mumbai) and Simla (Orlebar, 1846). Under the aegis of the GMU, three magnetic stations were set up at Chennai (1792), Simla (1841) and Travancore (Thiruvananthapuram, Trivandrum; 1841) and a few campaigns were organized at places like the Agastya Malai hills in today's Tamil Nadu state (Broun, 1874). Geomagnetism, as a branch of science, however, was firmly ensconced and institutionalized in the Indian subcontinent with the establishment of the Colaba-Alibag magnetic observatory.

Historical instrumented records identify trends and periodicities, helping to understand past variations. These can then be used to predict future changes. The long-series Colaba geomagnetic data available since 1841 can unravel exciting features associated with Earth's magnetic field changes, which needs to be brought, yet again, to the notice of the scientific fraternity. Hence, only the Colaba data are discussed. The magnetic disturbances, in those days, were described in terms of a "disturbing point" on Earth. Dr. Nanabhoy Moos, however, argued to the contrary, relating those to atmospheric activities. His role in shifting Colaba Observatory to Alibag is also outlined.

\section{Setting up Colaba Observatory}

\subsection{Status of Mumbai in 17th and 18th century India}

Mumbai in the early 15 th century was a lush and verdant collection of seven islands (Fig. 1) that had a small native population. Gerald Aungier, the second Governor of Mumbai, took possession of Colaba and Old Woman's Island in 1675 from the Portuguese, who ceded all Mumbai islands to the British King Charles II (Malabari, 1910). Aungier offered inducements to skilled workers and traders to set up businesses in Mumbai, resulting in a 6-fold population rise between 1661 and 1675 (Malabari, 1910). In 1743, Colaba was leased to Richard Broughton at Rs. 200 per annum and by 1796 had turned into a cantonment for troops (Da'cunha, 1900). A meteorological observatory (Fig. 2) was established in 1826 by the East India Company at the southern end of the island, called Upper Colaba, made up of a large transit room and two domes (Fig. 3; Orlebar, 1846). One of the domes stood on the ground, separate from all other buildings, and the other, bigger, dome was built over the superintendent's

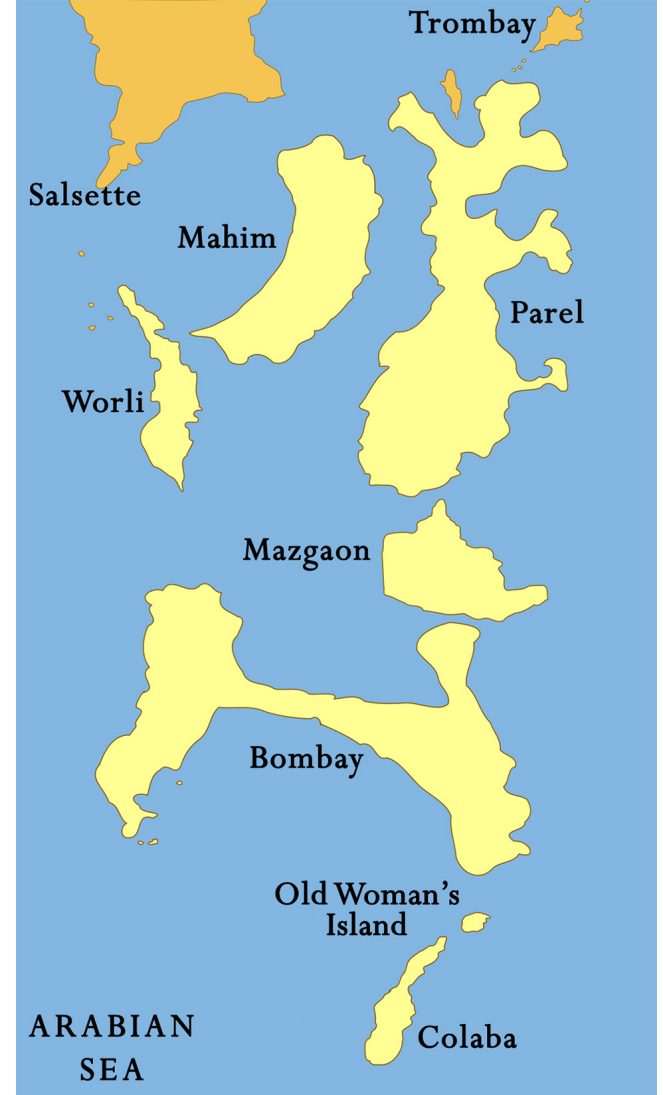

Figure 1. The collection of islands (modified from Kamath, 2000), separate and disparate, in the early 19th century that formed the Mumbai (Bombay) of today. Mumbai has developed from a bunch of virgin islands that were fused together to turn it into a bustling world-class metropolis.

quarters. It had an access through a winding staircase from the transit room, to which it was attached, and formed the western wing of the residence. The astronomical department was set up to provide the correct time by observing the transit of the stars to ships in the harbor, at 13:00 daily (Orlebar, 1846).

\subsection{Aden to Mumbai}

The Colaba magnetic observatory had a serendipitous start. The Royal Society wanted to install some magnetic instruments at Aden, now in Yemen (Orlebar, 1846). But, the officer responsible for taking charge had an untimely death, forcing the society to leave the instruments behind at Bombay astronomical observatory. Arthur Bedford Orlebar, professor of astronomy at Elphinstone College, Mumbai, took possession of these instruments on 15 March 1841 from Colonel Sykes, even though he was not familiar with their operation (Orlebar, 1846). The Royal Society had sent manuals with the instruments. However, Orlebar was not able to locate them. Hence, he sought Captain Boileau's help, who was the 


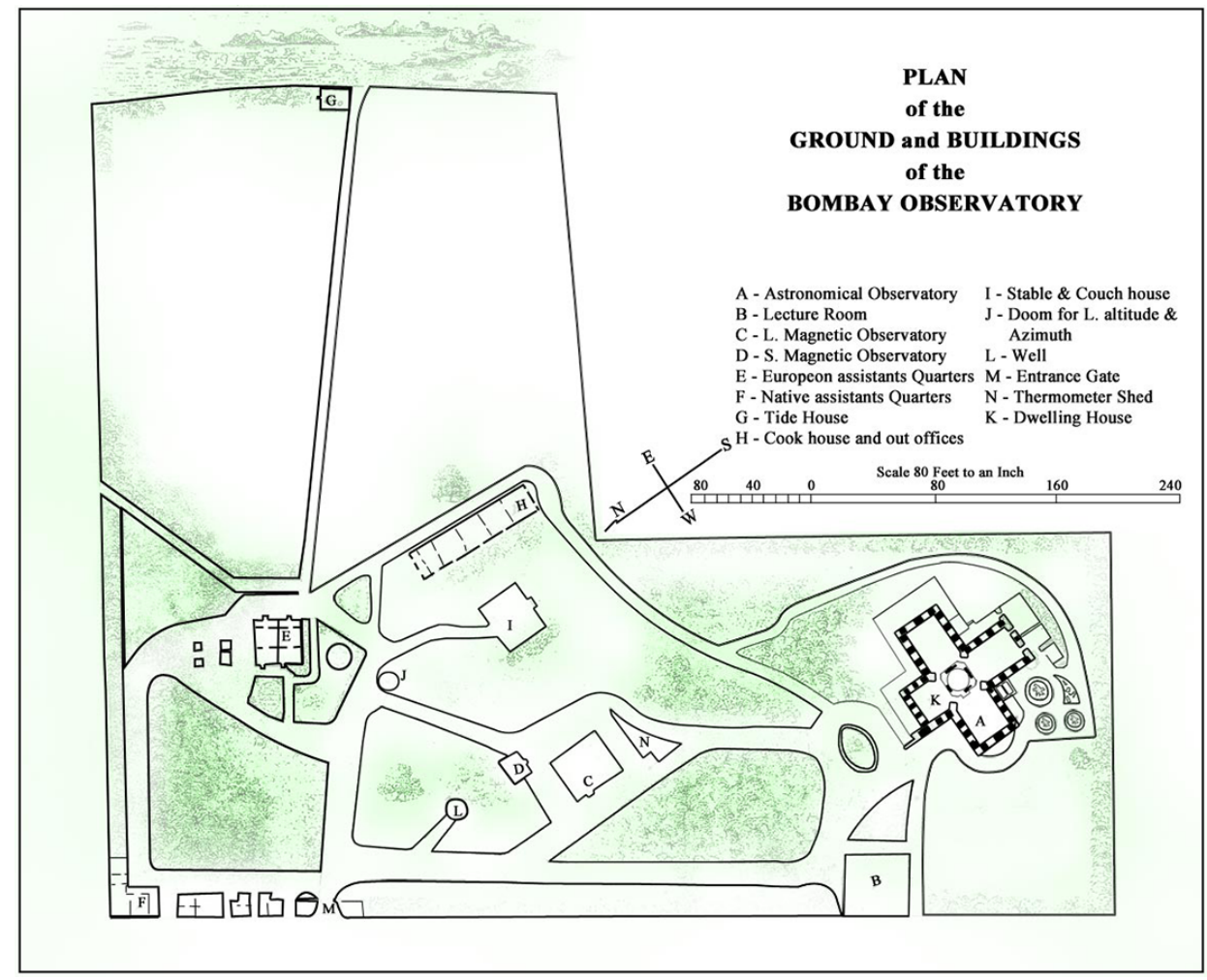

Figure 2. Meteorological observatory and magnetic observatory plan. The meteorological observatory established in 1826 by the East India Company made some room for magnetic instruments in 1841. Once installed, these magnetic instruments carved a niche for themselves and immortalized the place as the Colaba magnetic observatory (Orlebar, 1846).

superintendent of Simla Observatory (Orlebar, 1846). But, before Boileau's advice could arrive, Caldecott, the superintendent of Travancore Observatory, then passing through Mumbai, familiarized Orlebar with magnetic instrumentation techniques. The first magnetic observations at Colaba were recorded in 1841-42 under Orlebar's supervision. The first volume containing data of magnetic (and meteorological) observations from April to December 1845 was published in 1846 (Fig. 4), along the format set by Greenwich and Toronto observatories (Orlebar, 1846).

\section{The Colaba Observatory instruments}

Captain Goodfellow, superintending engineer, built the small observatory at the northeastern direction of the large observatory (Fig. 5) in 1841 to install magnetic instruments diverted from Aden to Colaba. At the time, great care was taken to ensure no magnetic material remained embedded in the construction material or around the observatory. Also, the installation of instruments at optimal distances from one another was meticulously planned such that the differences between their readings did not exceed a few nT. But, the installation was delayed because Orlebar was unable to formulate mathematical theories of the magnetometers. After sorting out these issues, Orlebar and his student Keru Laxman per- manently fixed the magnetographs in September 1841 (Orlebar, 1846). Staying in India was taking its toll on Orlebar's health, so he left for England on 1 May 1842. But, before his departure, three non-commissioned officers from Sappers and Miners were sanctioned who arrived at the observatory on 11 October 1841. Orlebar returned from England in April 1846 to find Sergeant Dunn, Keru Laxman, Ananta Ballal, Ganesh Narayan, and Dinshaw Dorabjee operating as observatory staff. $\mathrm{He}$ also found the observatory equipped with a unifilar magnetometer or small declination magnetometer, a bifilar magnetometer or small horizontal force magnetometer, an induction magnetometer, and a portable declination magnetometer detailed by Riddell (1844).

\subsection{Instrument placement}

The large observatory's foundation was made of shell sandstone, a floor of mud, walls of bamboo, and a roof of cajan (clay tile) (Orlebar, 1846). Nine windows streamed in natural light. Through the center of the roof and, dividing the wall, ran the transit slit, which was closed by shutters. The bamboos were cut at the top to allow cool air circulation under the ceiling. The temperature was evenly maintained by two copper ventilators placed along the northern and eastern walls. The thermometers and hygrometers were placed 


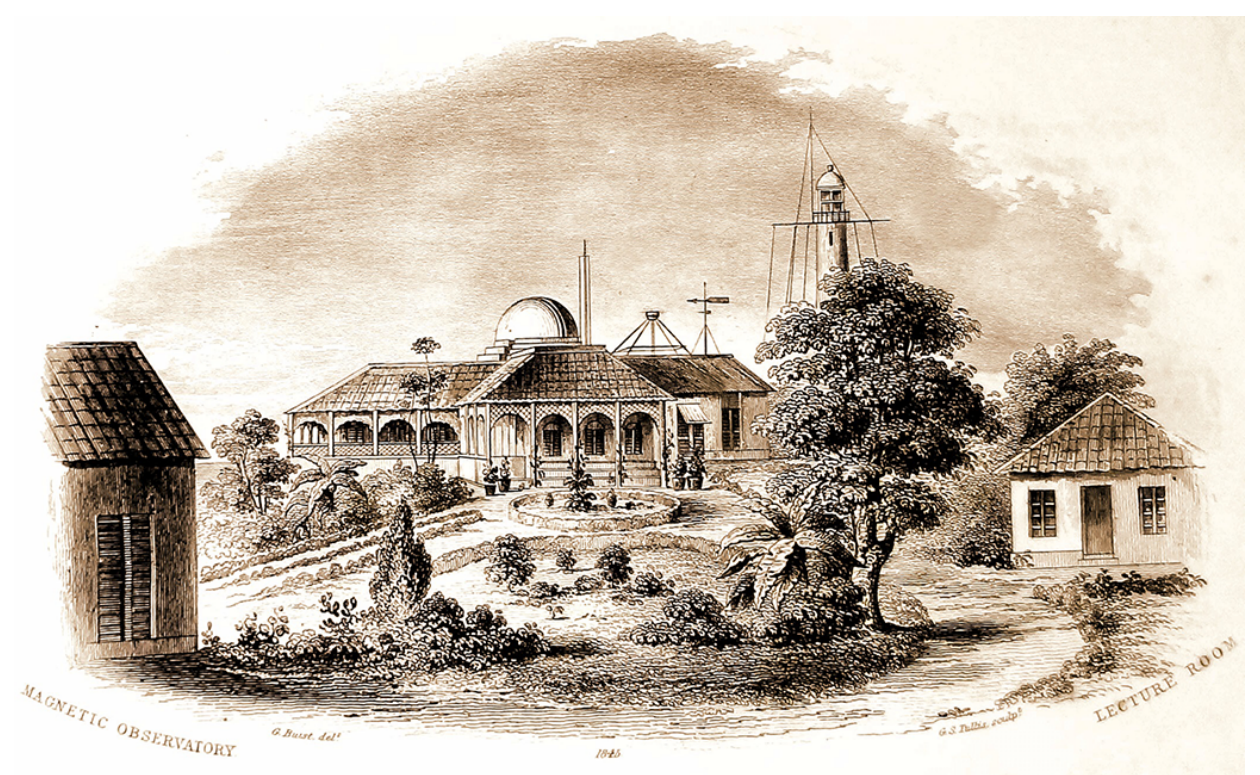

Figure 3. Photograph from the cover of the provisional report on the meteorological observations made at Colaba, Bombay, for the year 1844. The magnetic observations were carried at the far left end of the photograph partially depicting a hut. The lighthouse and dome are seen in the background.

on stand $M$. This stand was kept in the line of an air current passing through windows $E, W, W 6$ and $W 2$. The other windows functioned to let in as much air as possible. The barometer was fixed on a wall at $B . C$ was a stand for chronometers and $T$ the tables where registers were kept for office work. At $d$, a portable declination magnetometer stood and its theodolite for reading was at $t$. The declination magnetometer was kept under the transit slit about $2 \mathrm{ft}$ from the northern interior wall of the building, and the reading telescope on a block of teak. The position of these instruments is given in Fig. 6, in which $D$ is declination, and $H$ horizontal and $V$ vertical force magnetometers (Orlebar, 1846).

\section{Challenges of data acquisition}

Magnetic recordings at Colaba were carried out for almost 63 years under very challenging circumstances. The data at Colaba were acquired through eye observations from 1841 to 1872 and by photographic (magnetograph) series from 1872 to 1905 , the details of which are given in sections that follow. The year 1872 was common to these two sets of instruments.

\subsection{Declination $(D)$}

In 1845, an eye-observation declinometer, manufactured by Grubb of Dublin, was mounted at Colaba, but its record is available only from 1846 onwards (Chambers, 1888). To determine absolute $D$, a transit instrument by Dolland (Fig. 7) was placed in the meridian line of $D$ (Orlebar, 1846). Absolute $D$ was initially derived from readings of differential instruments by the formula $D=a(s-z) c$, where $D$ denotes absolute declination, $s$ the scale reading, $a$ the value in arc of an unit of the declinometer scale, $z$ the zero of the scale or zero reading corresponding to true astronomical north, and $c$ the torsion coefficient (Moos, 1910a). The readings were taken with a transit instrument fixed at a distance of about $27 \mathrm{ft}$ from the declinometer (Chambers, 1888).

Diurnal declination changes were observed hourly by the large and small declinometers no. I. It was customary to quote the dimensions of magnets in parts of foot and grain (1 grain equaled 64.79891 milligrams). The bar magnet of the large declinometer was $1.25 \mathrm{ft}$ in length, had a breadth of $0.0715 \mathrm{ft}$, was $0.0208 \mathrm{ft}$ thick and weighed 0.6203 grain (Montriou, 1851). The small declinometer was placed on a $4 \mathrm{ft}$ high wooden pillar. The magnetometer box was attached to a pillar with a white lead and scale read with the reading telescope. This telescope was fixed to a wooden pillar $5.5 \mathrm{ft}$ away from the magnetometer. A solid cylindrical magnet marked A54 remained suspended by two 0.30 in breadth and 2.990 inch long silk threads (Chambers, 1888).

\subsubsection{Reference marks}

The chimney of Tardeo Mill situated $\sim 5$ miles to the north and the tower of the Kennery lighthouse (Fig. 18) around 13 miles to its south were used as reference marks (Robinson et al., 1872). The azimuths of these marks were determined by star observations that were repeated for accuracy. The values derived and adopted in the reductions were $0^{\circ} 26^{\prime} 26^{\prime \prime} \mathrm{E}$ and $179^{\circ} 49^{\prime} 30^{\prime \prime} \mathrm{E}$, respectively, for the Tardeo chimney and the Kennery lighthouse (Moos, 1910a). The readings of the Tardeo chimney were invariably used in the reductions of the 


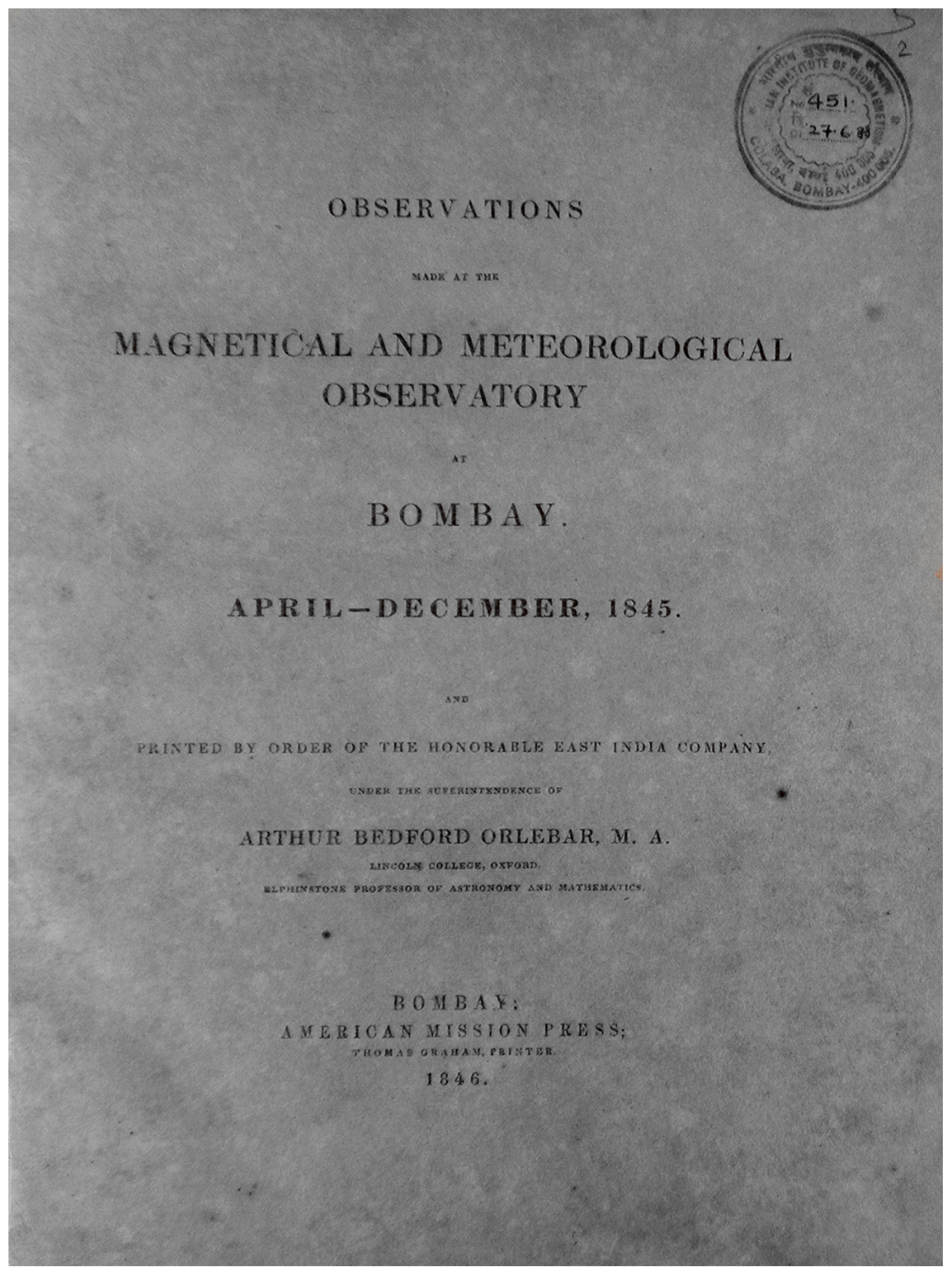

Figure 4. The cover page of the first volume reporting magnetic and meteorological observations at Colaba. It contains a detailed history of how magnetic instruments reached Colaba and the teething problems experienced in its initial years (Orlebar, 1846).

absolute determinations of declination. Observations of these two reference marks were made every week unless heavy rain or fog rendered the Kennery lighthouse invisible during the monsoon months and occasionally also during winter (Moos, 1910a).

\subsubsection{Declination measurement challenges}

Diurnal variations recorded between two horizontal force magnetometers installed in close proximity are expected to be similar. However, this was not the case in 1845 at Colaba. The reasons for anomalous diurnal variation (Orlebar, 1846) between large and small magnetometers (Fig. 8) were investigated by Charles William Montriou, the then superintendent, who placed the blame on hygrometric changes (Montriou, 1851). The humidity was acting variably on suspension wires of these two magnetometers. The silk thread suspension of a large magnet remained immune to these changes, but that of a small magnet was affected considerably. The 


\section{BOMBAY}

MAGNETICAL OBSERVATORY

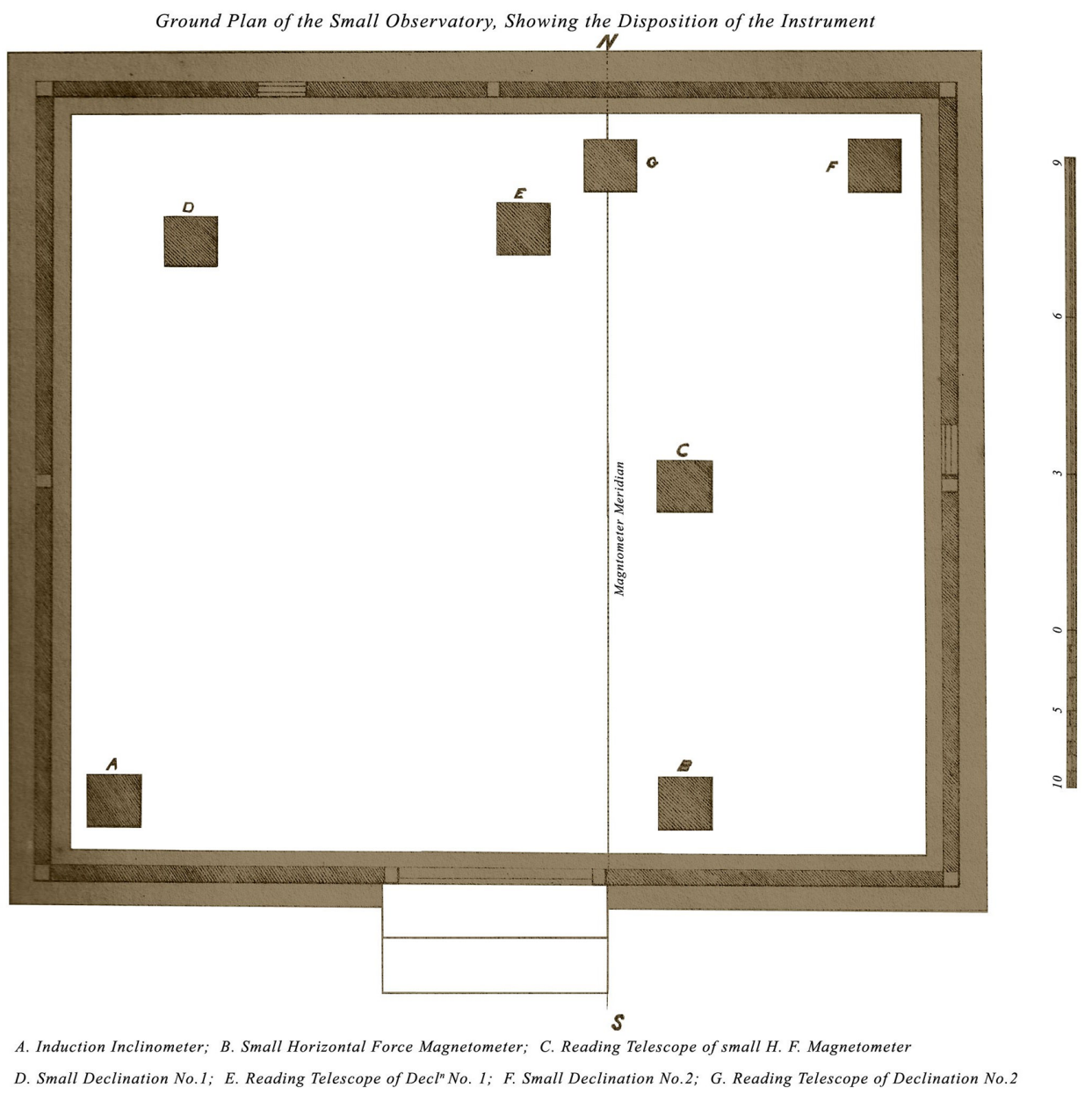

Figure 5. The arrangement and placement in a small observatory of magnetometers, induction inclinometers and other instruments (Orlebar, 1846).

magnetic measurements were also found to be affected by temperature changes (Montriou, 1851).

The Kew Observatory and its committee were a nodal agency safeguarding and maintaining high standards for instrumentation. Between 1853 and 1897 it tested and calibrated 21 magnetographs, 117 unifilar magnetometers, 155 dip circles, and a number of collimating magnet tubes and dip needles (Multhauf and Good, 1987). A photographic selfrecording instrument designed by Elliott Brothers (Fig. 9), which was examined and tested at Kew Observatory by Dr. Balfour Stewart, reached Colaba in June 1867 (Robinson et al., 1872). Stewart also determined the values of constants, essential for deriving absolute $D$, and for deflection and vibration experiments from which absolute $H$ were determined.

This Kew declination magnetograph was installed in the underground room along with other magnetographs, late in the year 1870 , from which a continuous record from January
1871 to March 1906 is available (Moos, 1910a). The magnet was suspended by about six silk fibers bunched together to facilitate its orientation in magnetic meridian (Moos, 1910a), potentially affecting the residual torsion in the suspension skein. Since the instrument was used for differential purposes, the variable torsion did not matter much. The magnets were dipped in a solution of shellac and alcohol to minimize the effects of moisture. The magnet and two mirrors, after adjustments, were fixed in an enclosure whose pressure was maintained to about 3 inches of mercury. However, the enclosure continued to hold some moisture till 1876, after which the problem was rectified.

\subsection{Horizontal force $(H)$}

$H$ was derived from two sets of instruments. The absolute $H$ was determined by Grubb's magnetometer (eye observations) during 1847 to 1867 and by unifilar magnetometer 
$B O M B A Y$

MAGNETICAL OBSERVATORY

Ground Plan of the Large Observatory, Showing the Disposition of the Instrument

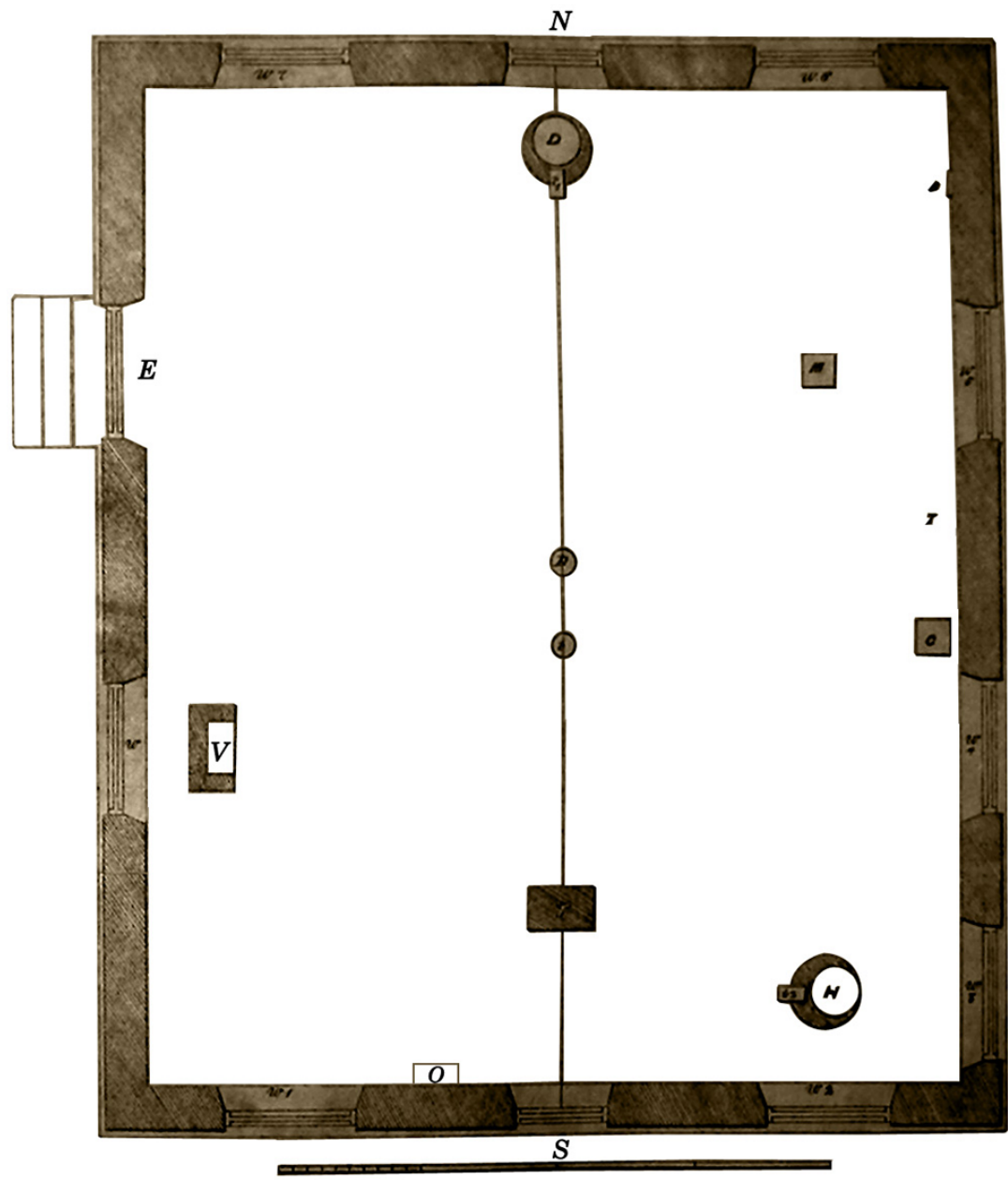

D. Large Declination, V. Verticle Force, H. Horizontal Force

D. Small Declination Magnetometers, NS Astronomical Meridian

T. Small Transit; B. Barometer; C. Chronometer; M. Meteorological Stand;

$t, t 1, t 2$, Reading Telescope, E. Door; O. Mean Time Clock

Figure 6. The placement of different instruments is depicted in this plan of the large observatory (Orlebar, 1846).

no. 23 by Elliott Brothers (photographic) from 1868 to 1905 (Moos, 1910a).

The large horizontal force magnetometer designed by Grubb of Dublin, and a bifilar or small horizontal force magnetometer, were also used to determine diurnal changes in $D$ (Orlebar, 1846). The former was installed in the large observatory and the latter in the small observatory. The adjustments of the instrument were made by ascertaining the effect of temperature on the magnet by immersing it in hot water. It was then vibrated in the declination apparatus to determine constant values of the instrument (Orlebar, 1846). Since these instruments were small and the spiders interfered with the readings, they were enclosed in a cylindrical box (Orlebar, 1846). The box was covered externally with cloth and internally by gold paper to minimize any form of internal radiation (Orlebar, 1846). The cover of the torsion circle was fixed in wax and fastened with strips of cloth to plug off all the crevices. The magnetometers were heated with charcoal to ascertain the intensity in order to minimize the creep of the magnet (Orlebar, 1846).

The horizontal force differential instrument was mounted in 1840. The records (Fig. 10), however, are available from 1846 onwards till 1905, with some interruptions in December 1850, December 1855 and January 1873 (Moos, 1910a). 


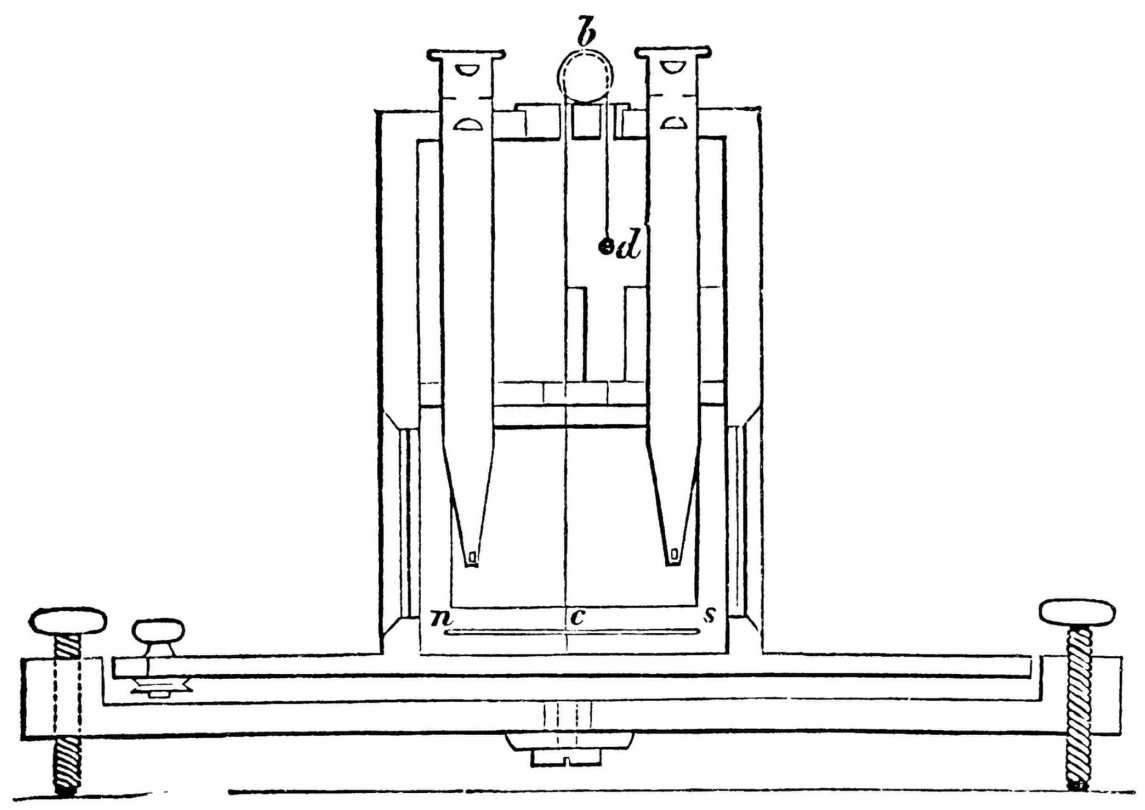

Figure 7. This is the diurnal variation instrument designed by George Dolland and manufactured around 1825 (Multhauf and Good, 1987) that was used for recording declination changes. A similar instrument existed at Colaba and later on at Alibag.

Hourly eye observations of this instrument were made continuously on all days of the week, except on Sundays and holidays during the period 1847-1872 (Moos, 1910a). The magnetographs were introduced late in 1871 and in 1872 both these differential instruments operated simultaneously. These simultaneous records were used to understand variations encountered before and after 1872 (Moos, 1910a). Hourly observations by Grubb's magnetometer were discontinued in 1873 and eye readings at only 06:00, 10:00, 14:00, 16:00 and 22:00 were taken till the closure of Colaba recordings (Moos, 1910a).

\subsection{Vibration and deflection experiments}

The absolute instrument used from 1847 to 1867 had many shortcomings like incomplete formulae adopted for the reductions, innate instrumental errors, and consequent uncertainties in observations, leading to faulty determination of constants (Moos, 1910a). The observations carried out from 1868 to 1905 by Kew unifilar magnetometer no. 23 of Elliott Brothers, (Moos, 1910a) were in two parts: (1) the vibration experiment that gave $m H, m$ being the moment of the magnet used and $H$ the horizontal force of the Earth's magnetism; and (2) the deflection experiment that generated $m / H$. These results were then combined to derive $m$ and $H$.

In the first experiment, the equation that gave the time of a complete vibration of the magnet is

$T=\sqrt{4 \pi^{2} k / m H(1+\tau)} \quad$ or $m H=4 \pi^{2} k / T^{2}(1+\tau)$,

where $k$ is the moment of inertia of the magnet and $T$ the torsion of the suspension skein.
In the second experiment, the equation of equilibrium is

$$
\begin{aligned}
& \frac{r^{3} H}{2 m} \sin u=1+\frac{P}{r^{3}}+\frac{Q}{r^{4}}+\ldots, \\
& \text { or } \frac{m}{H}=\frac{r^{3} \sin u}{2} / 1+\frac{P}{r^{3}}+\frac{Q}{r^{4}}+\ldots,
\end{aligned}
$$

where $\mu$ is the angle of deflection, $P, Q$, etc., the constants of distribution of magnetism, and $r$ the distance between deflecting and deflected magnets. Kew Observatory supplied the induction and temperature constants (Moos, 1910a).

For values of $H$, deflection observations at Colaba were taken at 0.8 and $1.0 \mathrm{ft}$, after which the correction for distribution of magnetism was applied (Moos, 1910a). A double set of observations was taken every week, consisting of a "vibration" (Fig. 11) and "deflection" (Fig. 12) experiment.

Magnetometer observations at Colaba were made to accurately determine the value of $H$. Theory on interaction of two magnets states that the distance between them should be more (Fig. 13) than half the length of the (larger) deflecting magnet (Moos, 1910a). The moment of the Colaba magnet diminished from 0.716 to 0.618 , overestimating $H$ by about $8 \mathrm{nT}$ in 1868 . This overestimation came down gradually to about 2 or $1 \mathrm{nT}$ in a span of 35 years from 1868 to 1903 (Moos, 1910a). This was verified by comparing the standard instrument with four different magnetometers (Moos, 1910a). Measurements by the Colaba standard instrument were carried at five distances, viz., 0.7, 0.8, 0.9, 1.00 and $1.30 \mathrm{ft}$, to aid in comparison (Moos, 1910a). 


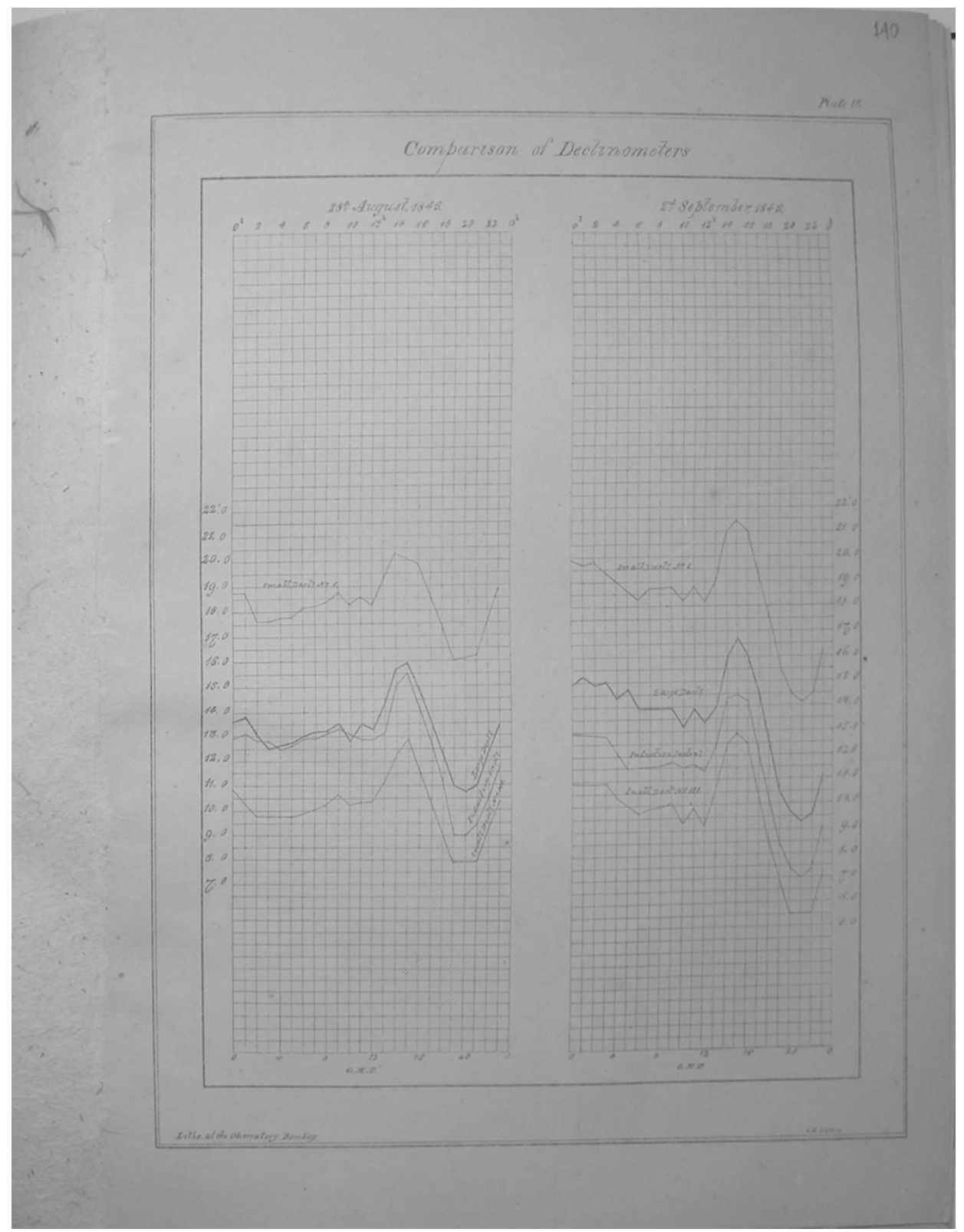

Figure 8. Comparison of declinometers carried to ascertain reasons for anomalous diurnal variation (Orlebar, 1846).

\subsubsection{Self-recording differential magnetograph}

A self-recording Kew-type $H$ differential magnetograph was installed at Colaba Observatory in 1870 along with similar instruments to record variations in $D$ and $Z$ (Chambers, 1888). According to the description given in Moos (1910a), the magnet remained suspended by two fine platinum wires separated by a small distance, called bifilar suspension. When there was no torsion, the magnet lay in magnetic meridian. At the same time, planes passing through the upper and lower extremities of bifilar wires also aligned along the magnetic meridian. On application of torsion to the upper ends of the wires, the plane passing through the lower end did not completely follow this motion. The force of the magnet to keep itself in magnetic meridian restrained free movement. This led to an angular difference between the upper and lower ends of bifilar, generating two couples. The first was the force of torsion that twisted the magnet away from the magnetic meridian. The other, caused by the action of terrestrial magnetic force acting on the moment of the magnet, constituted an equal and opposite couple that tried to keep the magnet in the meridian. This in effect generated equilibrium. The loss of equilibrium was attributed to terrestrial horizontal force changes. There were two mirrors attached, one to the magnet and the other to the base plate. The 


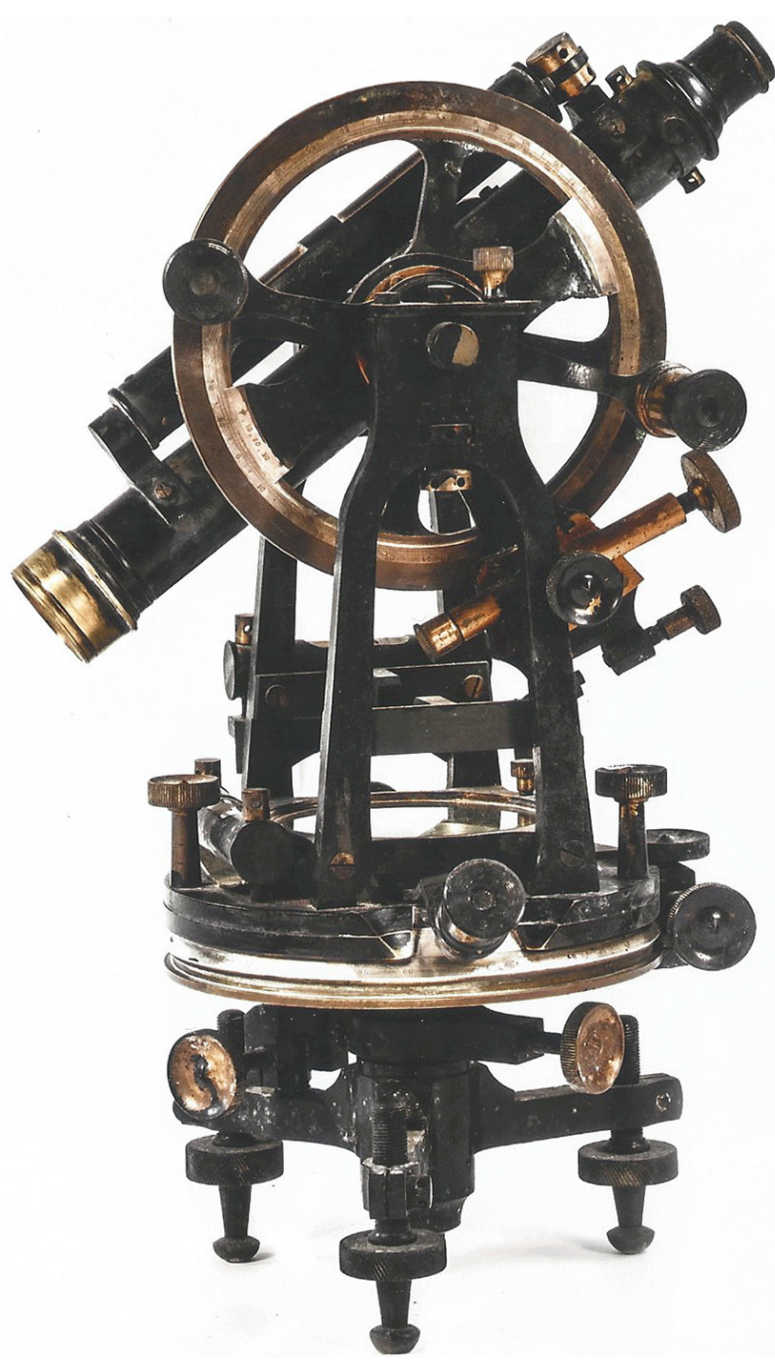

Figure 9. The Kew declinometer designed by Elliott Brothers was installed in 1870, but started recording in January 1871, which continued till 1906. It had a magnet and two mirrors with a vertical and horizontal scale (courtesy of Colaba-Alibag Observatory).

beam of light was reflected from the fixed mirror onto a photographic paper mounted on a cylinder rotating once in $24 \mathrm{~h}$. This gave a steady line called the zero line, whereas the light reflected from the mirror attached to the magnet gave a curve indicating variation in $H$. The scale attached to the magnet was read through the telescope (Moos, 1910a).

This magnetograph was adjusted or its record interrupted for some reason in May 1871, February 1872, October 1873, February 1877, July 1882, January 1885 , June 1888, July 1892, February 1898, and November 1903 (Moos, 1910a).

\subsubsection{Temperature and ageing of magnets}

The magnets used in instruments are normally magnetized to saturation. Such magnets tend to lose their magnetic mo- ments very rapidly and irregularly, allowing some inaccuracy to creep into the measurements. The rapid shifts in the "zero" or the baseline force the curve off the photographic paper, necessitating frequent adjustments to bring the curve back onto the recording paper, effectively lowering the efficiency of the instrument. The differential instruments then newly installed at Colaba came with small magnets that were aged appropriately to remove excess magnetization (Moos, 1910a).

Temperature affects the efficiency of magnets, making it necessary to protect them from large temperature changes and to alternatively choose magnets with small coefficients. The former can be achieved by constructing special rooms having uniform temperature, but the latter is more difficult to achieve, needing elaborate experiments. The temperature coefficient of the magnet can be derived by three methods (Moos, 1910a). The first involves heating and cooling of the magnet, the second requires simultaneous temperature and scale reading of the instrument, and the third deals with heating and cooling of the magnetograph room. The last method was adopted at Colaba, wherein the magnetograph room was periodically heated and cooled. This method gave the scale coefficient of the instrument and temperature coefficient of the magnet, making the instrument ready to obtain absolute values (Moos, 1910a).

\subsection{Vertical force $(Z)$}

Though the vertical force magnetograph was added to Colaba in 1870 (Chambers, 1888), recording by it commenced regularly only from 1873, which continued till 1905 (Moos, 1910a). However, a microscopic shift was noticed in the magnetograph magnets' center of gravity. Hence, a new magnetograph was installed in 1892 in the underground chamber to secure a reliable and unvitiated record. Recording by the old and new instruments (Fig. 14) ran concurrently from 1893 to 1905 , helping to formulate the necessary corrections for the older series to bring them on par with each other (Moos, 1910a).

\section{Working principle}

$Z$ was measured using Robinson's balance magnetometer or the vertical force magnetometer whose working principle can be found in Moos (1910a). According to Moos (1910a), when a magnet balances itself in the magnetic meridian at a place like Mumbai, the north end of the magnet dips down. This shifts the dipping magnet's center of gravity northward proportional to the angle of inclination at Mumbai. To keep such a magnet in a horizontal position, it is balanced by weights compensating for the terrestrial vertical force. After this, if there is any change in vertical force, the north end either inclines downward or upward based on the increase or decrease in force. Like other magnetographs, this instrument also had a mirror attached to the magnet, and in close proximity to it was placed the zero mirror fixed to the base 


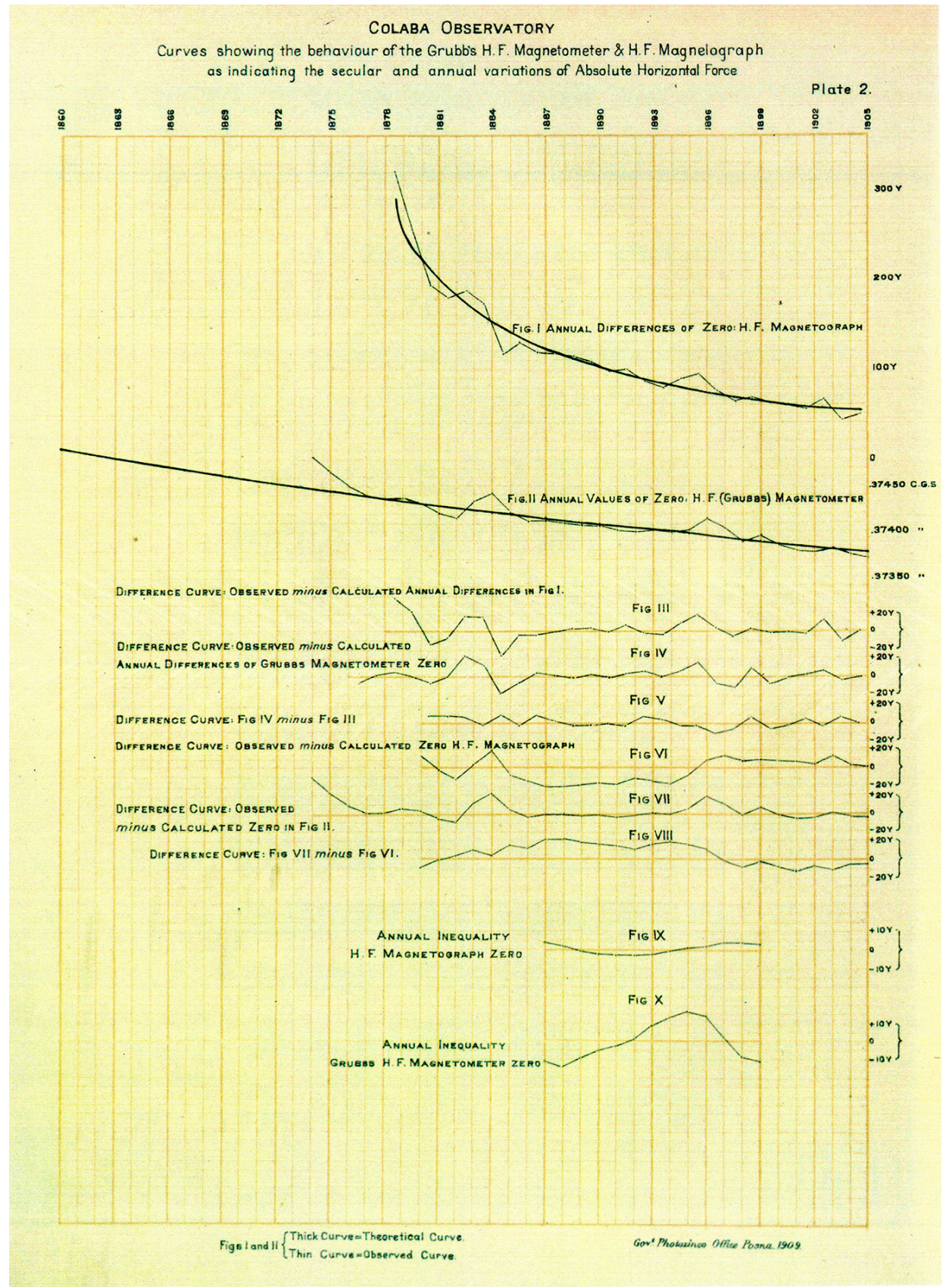

Figure 10. Photograph showing secular and annual variations of absolute horizontal force (Moos, 1910a).

of the instrument plate. A reading telescope and scale were also attached to the magnetograph for eye observations. The adjustments to this instrument were carried out in 1893, after which the balance remained untouched. The temperature coefficient was determined by carrying out heating experiments over 3 days in January 1895. The underground chamber was heated to $\sim 40^{\circ} \mathrm{C}$ and allowed to cool to normal temperature (Moos, 1910a).

The balance magnetometer magnet was placed at right angles to magnetic meridian on the suggestion of the Royal So- ciety (Chambers, 1888). The changes in this component were obtained by means of micrometer readings. However, this instrument had certain manufacturing defects and some other lacunae (Moos, 1910a). The magnet had lost its sensitivity and monsoon compromised its accuracy since the moisture ate away at its axis and slow increases in readings were observed for some months. At certain other times, however, it remained fairly constant (Moos, 1910a). 


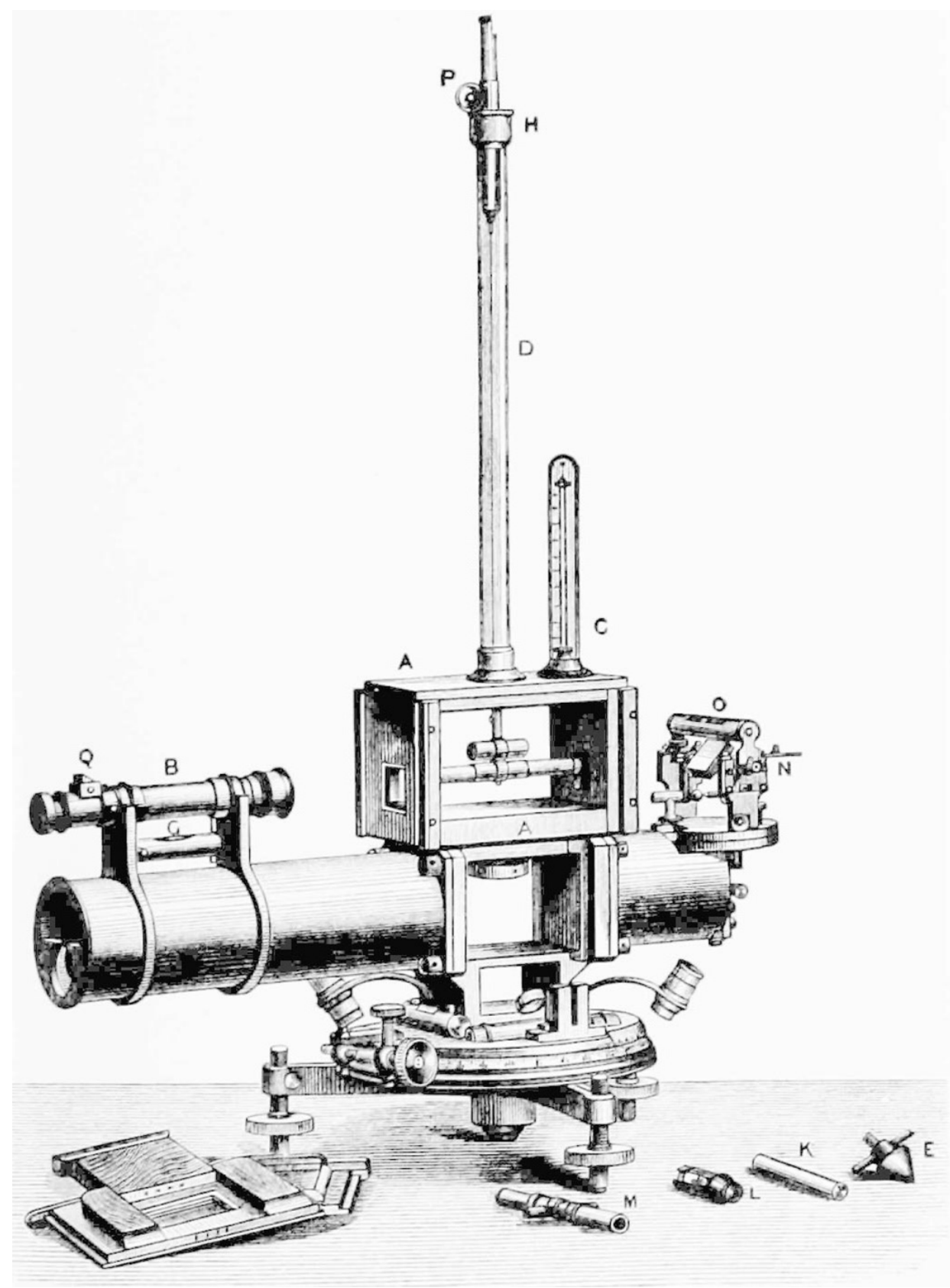

Figure 11. This instrument dealt with vibrations for intensity measurements, which were calibrated at Kew Observatory (Multhauf and Good, 1987). In fact, the vibrations were initiated in such a fashion as to avoid vertical vibrations. During the process, torsion-free suspension fibers were used.

\subsection{Inclination (/)}

The tendency of the compass needle to point downward or upward from the plane of the horizon is called dip or inclination. The instrument used for measuring $I$ was called the dip needle, dip circle, or inclinometer. In the earliest phase, it was called the dip circle.

\section{Instrumentation}

From 1846 to 1867, I observations (Robinson et al., 1872) were carried out by Barrow of London's old pattern dip circle (Fig. 15). This instrument came without a microscope and $I$ was read directly from the minute scale. The needle falling on the scale was 6 inches long, which was cleaned with emery paper. This compromised the accuracy of the instrument; hence, the data from 1846 to 1867 are considered 


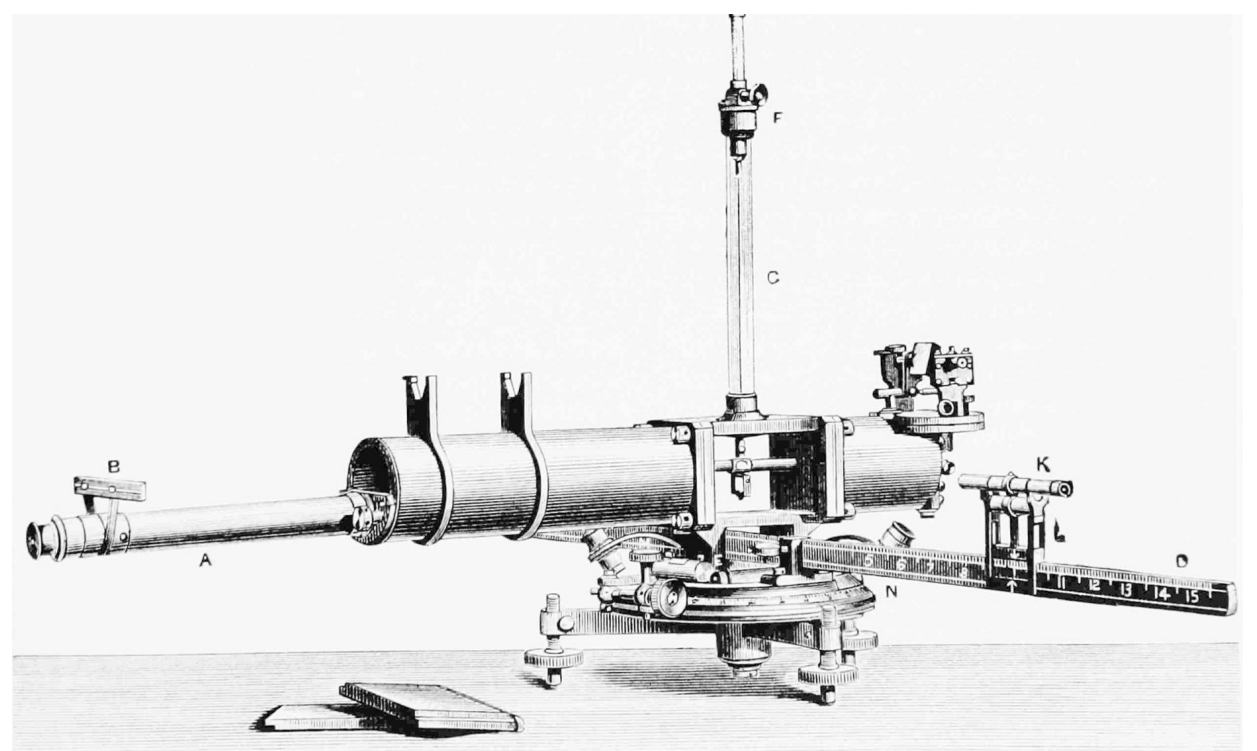

Figure 12. This is the deflection magnetometer designed and calibrated at Kew Observatory (Multhauf and Good, 1987). The magnets were kept on the scale, shown on the right, at different lengths to measure the deflection of the suspended magnet to derive $H$ and $m$. This process was continued on the opposite side as well.

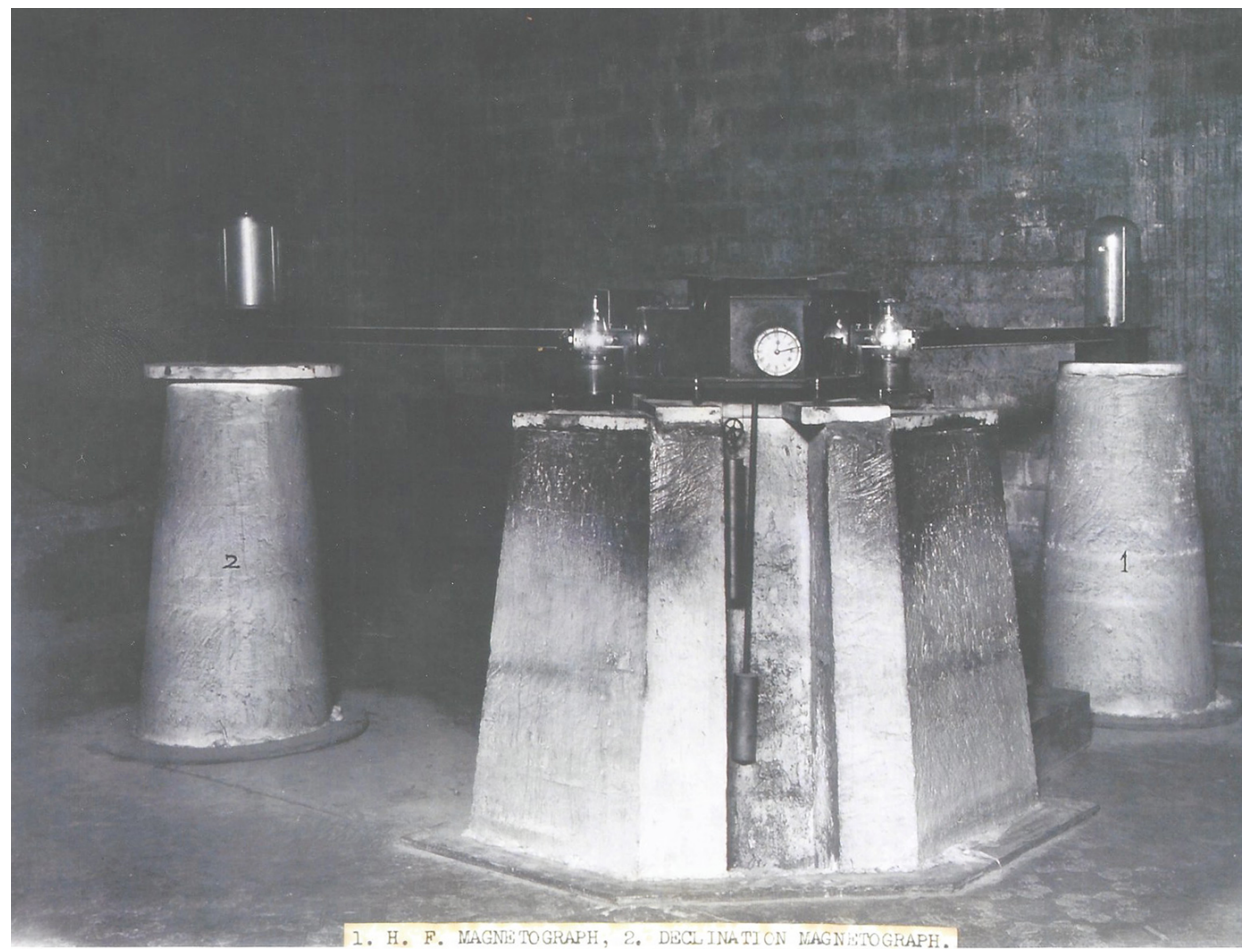

Figure 13. Arrangement of pillars and magnetometers that existed at Alibag. The pillars were meant for sensors. The $H$ magnetometer was placed on top of the pillar marked 1 (extreme right). The $D$ magnetograph was kept on pillar 2 (extreme left). The center pillar had a clock and bulb for deflection and vibration experiments. Recording drums were installed on separate pillars. The recording drum had a chain and weight arrangement (courtesy of Colaba-Alibag Observatory).

unreliable or at best a very rough measure of $I$ (Robinson et al., 1872; Moos, 1910b). Erratic readings also emanated from the dip circle from 1872 to 1887 because of adjust- ments carried out in 1877, 1881 and 1887 (Moos, 1910b). However, a theoretical curve derived for $I$ secular variation revealed its failure as an absolute as well as variation instru- 


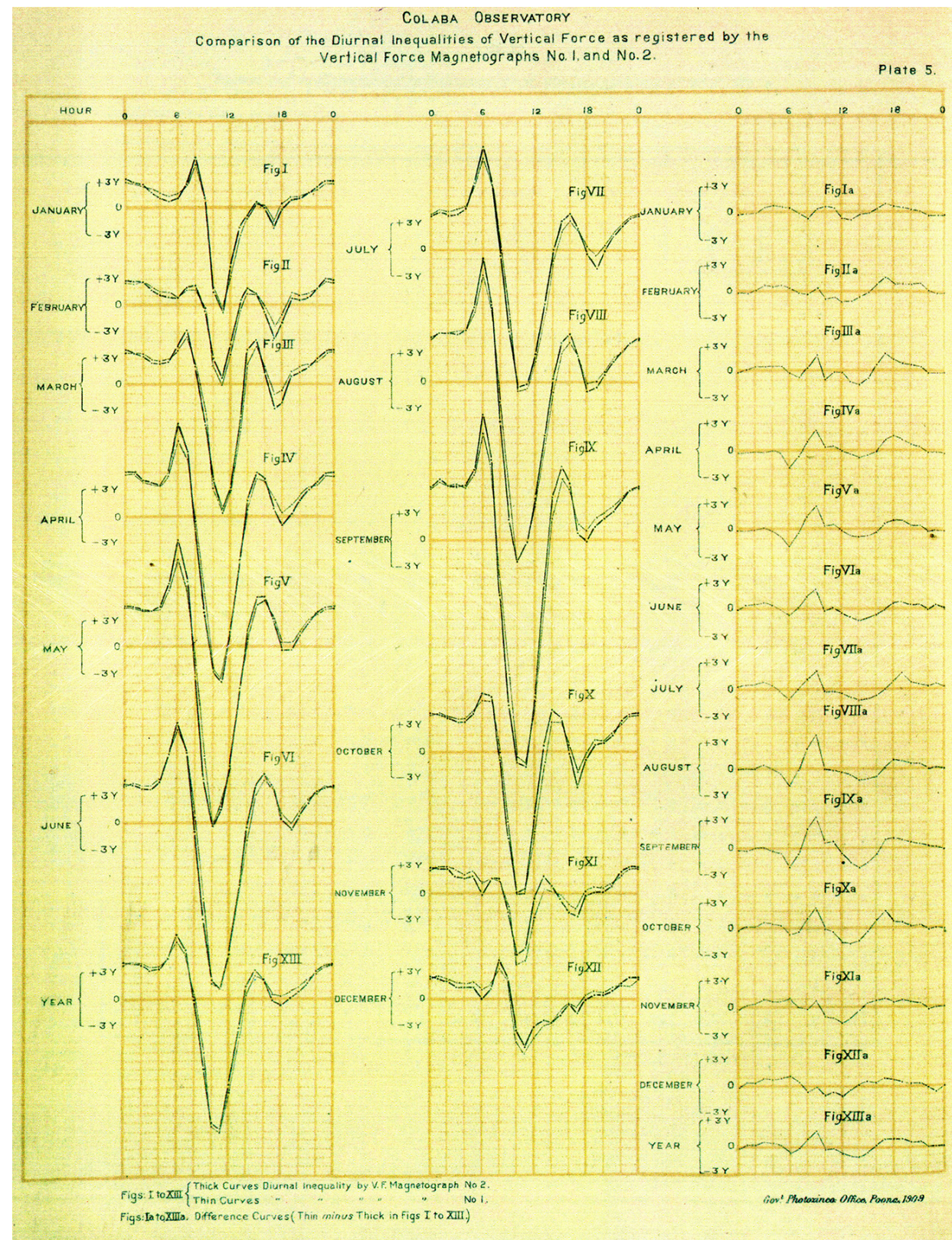

Figure 14. Photograph showing a comparison of diurnal inequalities of vertical force (Moos, 1910a).

ment between 1873 and 1887 (Moos, 1910a). Observations from 1888 to 1905 were found to correlate with results from three other dip circles received from England, and hence are treated as reliable (Moos, 1910b). This underlined the absolute necessity to record magnetic parameters with two or more independent sets of instruments at important observatories (Moos, 1910b).

Observations from 1867 to 1871 were made on the ground floor of the electrometer tower, and were later taken from the top of the tower from October 1871 (Moos, 1910b). A difference of 3 min of an arc was noted and corrected to integrate the 1867 to 1872 data series with that after 1871 . Obser- vations of inclination were made every Tuesday and Friday, comprising two complete sets (Robinson et al., 1872).

At the end of April 1867, another dip circle, examined and tested at Kew Observatory, was installed at Colaba (Robinson et al., 1872). Barrow of London manufactured it and numbered 49 , which had two 3.5 -inch needles designated numbers 1 and 2. The instrument consisted of a 6-inch horizontal circle read by a vernier to $1 \mathrm{~min}$, a revolving plate carrying a 6-inch vertical circle with two verniers, also reading to $1 \mathrm{~min}$, microscopes, and a pair of vertical pillars with $Y s$ for lifting the needle (Robinson et al., 1872). 


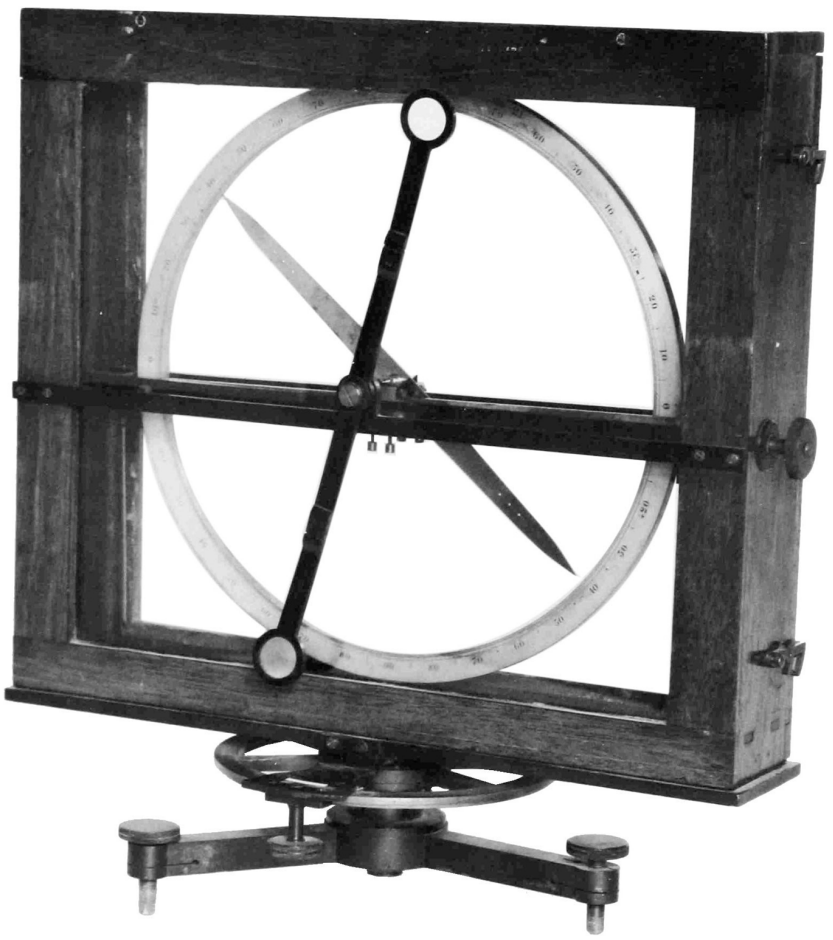

Figure 15. A similar dip circle manufactured by Barrow (Multhauf and Good, 1987) was in use at Colaba from 1846 to 1867. It was a simple apparatus without a microscope. The vertical movement of the scale was harnessed to find $I$.

\subsection{Routine tasks carried out at Colaba}

The photographic paper was mounted on the cylinder every alternate day, getting 2 days' curve on one magnetograph (Moos, 1910a). These were developed, fixed, washed and kept under running water for $12 \mathrm{~h}$, and were then hung up and dried. Moisture and temperature affected the paper film and tabulation of ordinate measurement acquired annual variation (Moos, 1910a). All these observations were tabulated in a special form along with the scale readings. Simultaneous ordinate and scale readings revealed a constant relation between them, provided that the telescope, scale and paper on which eye readings were secured remained unchanged (Moos, 1910a). The check constants were derived by tabulating ordinates that were converted into scale reading by factors 3.46 and 1.363, respectively, for an ordinate of 1 inch or $1 \mathrm{~cm}$ (Moos, 1910a). The value of the scale reading was then subtracted (added in the case of declination) from the observed eye reading (Moos, 1910a).

\subsection{Colaba geomagnetic element inferences}

Data recorded for $D$ before January 1856 are treated as unreliable, since the declinometer was subjected to repeated adjustments between 1846 and 1861. But, the values of zero were consistent from January 1856 onwards, which oscil- lated at around 28.3 of the scale division (Moos, 1910a). Simultaneous observations by the older and newer declination magnetographs carried out in 1871 and 1872 displayed a definite trend that was used to preserve continuity between the earlier eye observation and the later magnetograph series. Some minor problems were encountered in 1881, 1882, 1883, 1894, 1895 and 1896 (Moos, 1910a). During 1846 and 1872 , changes in $D$ were westerly during summer months and easterly in winter months. This matched with changes in Pavolovsky, Tiflis, Moscow, Paris, Trivandrum and Batavia, but differed from Greenwich, Kew and a few other places (Moos, 1910b). The monthly and annual values of zero (scale reading corresponding to the true astronomical north) rose steadily, attaining maximum in about $1890\left(57^{\prime} \mathrm{E}\right)$, and fell steadily thereafter till 1905 (10' E; Moos, 1910a). These changes were not affected by magnetic storms (Moos, 1910b) and are perceived to have been caused naturally and not due to instrumental errors. $D$ was deduced to be influenced by 13.5-day periodicity from 1888 to 1905 (Moos, 1910b). The trend is also apparent in the results of the horizontal force magnetograph zero (Moos, 1910a).

$H$ maximum was constant throughout the year at Colaba, but the minimum was season-dependent, and it also remained minimum during maximum and minimum sunspot periods between 1882 and 1905 (Moos, 1910b). Seasonal disturbances in $H$ during March and April were found to be opposite to those of December and January for the same period (Moos, 1910b). Bhardwaj and Rangarajan (1998) found a sharp depression in September and a steep rise in December in $H$ from 1924 to 1993 . The $H$ transition epochs or dates of average value attainment occurred at intervals of $\sim 5.5$ years (Moos, 1910b). The prolongation of this interval was observed between 1850 and 1858 and from 1897 to 1904 (Moos, 1910b). Practically identical results were obtained from the eye-observation data series of the Grubb horizontal force magnetometer (Moos, 1910b).

In a span of 37 years between 1868 and 1905, $Z$ rose at Colaba from 12874 to $15083 \mathrm{nT}$ (Moos, 1910b). Low $Z$ values existed during the maximum sunspot epoch and high values during the minimum (Moos, 1910b). The annual inequality of $I$, and $Z$, was influenced by 11 -year periodicity and the secular march of $Z$ was fairly parallel to that of $I$ (Moos, 1910b).

Bhardwaj and Rao (2013) found two-solar-cycle periodicity in $D$, and quasi-periodicity of three solar cycles in $H$ residuals for the period 1958 to 2009 at Alibag. Furthermore, Alibag data from 1927 to 1997 were analyzed by Bhardwaj (2009), who found a quasi-biennial oscillation-like signal with a periodicity of $\sim 24$ months and peak-to-peak variation in $H$ with sunspot numbers. 


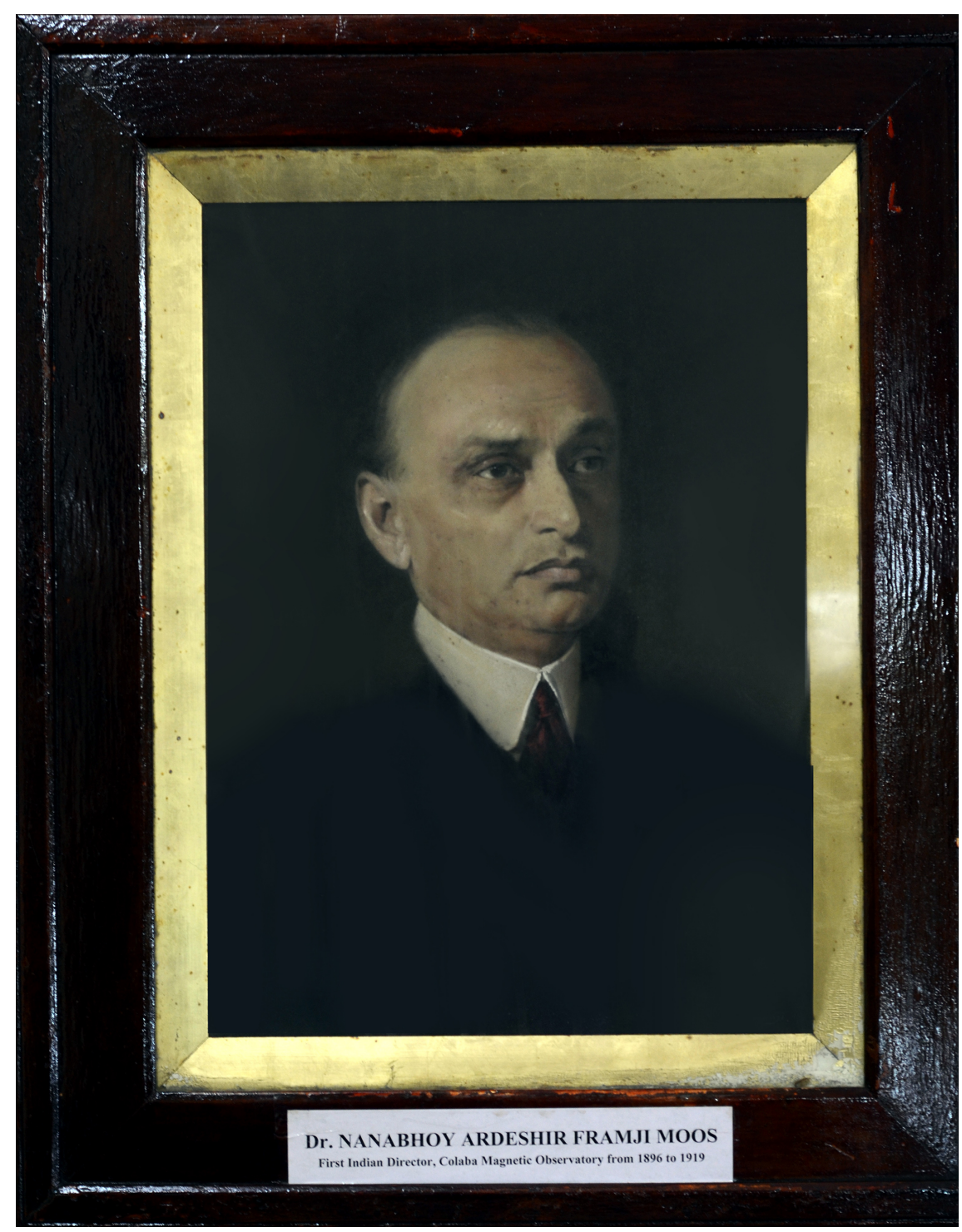

Figure 16. Photo of Dr. Nanabhoy Ardeshir Framji Moos, the first Indian director within the realm of colonialists, who held his own and even surpassed some of the best European minds of his time (photo courtesy of Colaba-Alibag Observatory).

\section{The genius of Nanabhoy Moos: the first Indian director}

The preceding sections have copious mentions of Moos (Fig. 16). He was the first "Indian" director of Colaba Observatory. He was born in 1859 on 29 October to an illustrious Parsee family involved in education and commerce. His great-grandfather founded this family when he came to Mumbai from Surat. Framroze, his grandfather, was a member of the first chamber of commerce and the native education society. His father Ardeshir was Professor of Natural Philosophy at Elphinstone College. Nanabhoy received his schooling at the Elphinstone School and, after matriculation at 16, joined the College of Engineering, Poona, earning his degree at the age of 19. He joined the Bombay Municipal
Engineering Service, but later joined his college at Poona to teach engineering. Moos went to Edinburgh for his BSc and doctorate studies. His first book, entitled "Strength of Materials and Strains in Structure", was published in 1886 by Griffith and Farren, London. He was appointed the director of Colaba Observatory in March 1896 on the demise of Mr. Charles Chambers. He established a time ball observatory at Manora, Karachi (now in Pakistan), and the magnetic observatory at Alibag (Unakar, 1936a). His treatise "Colaba Magnetic Data 1846-1905", published in two volumes, attests to his analytical powers. He meticulously and accurately documented all the observations carried out at Colaba Observatory, interpreting them in his own inimitable style. His insights into the Sun-Earth relationship, which hints at ionospheric currents and a profound conclusion that a small 


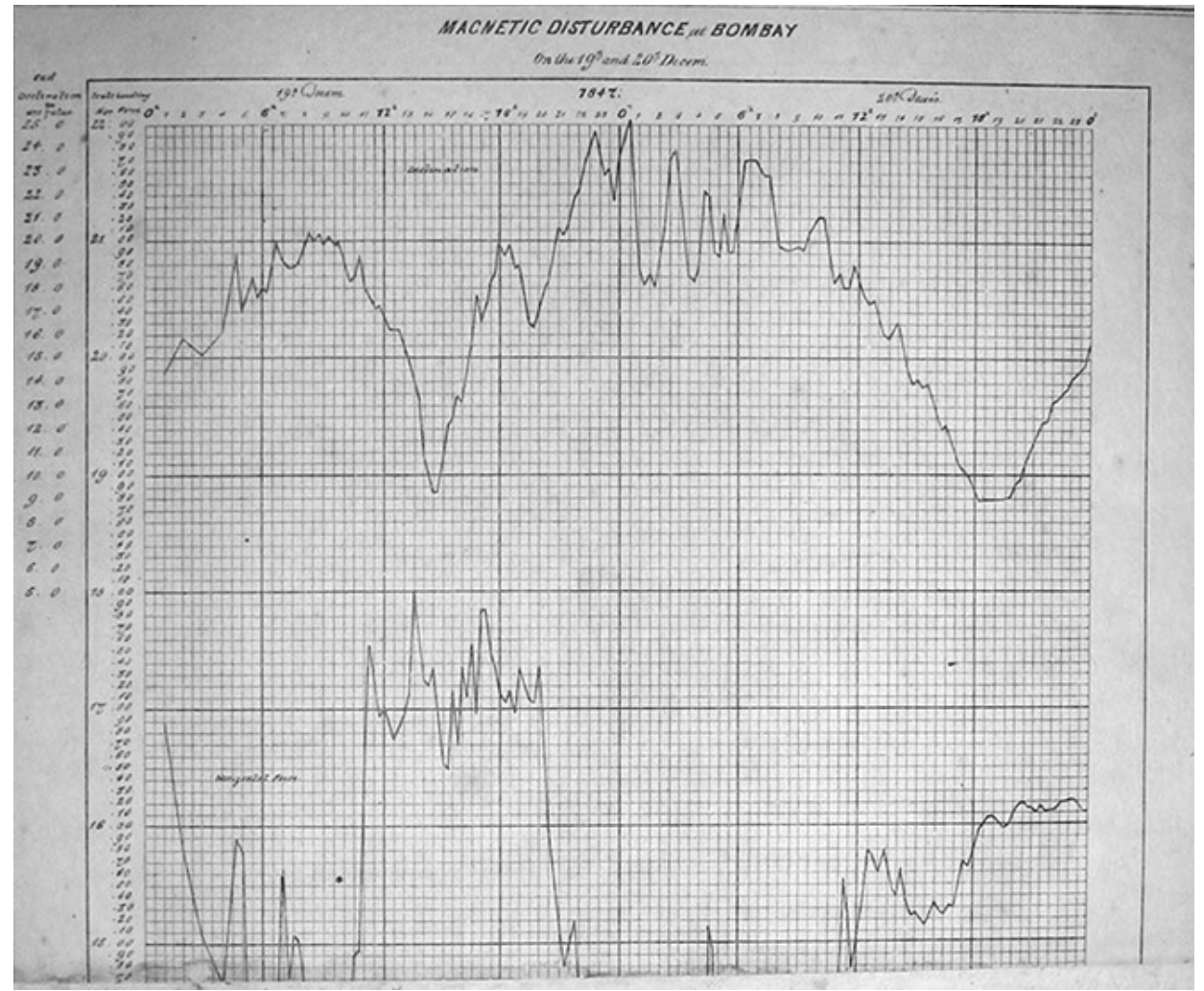

Figure 17. Magnetic disturbance recorded at Colaba on 19-20 December 1847 (Orlebar, 1846).

proportion of the Earth's magnetic field owes its origin to sources outside the Earth (Moos, 1910a, b), puts him far ahead of his times.

\section{Disturbing magnetic poles and Moos}

Magnetic storms (Fig. 17) are common and recurring phenomena. The term "magnetic storm" was not used in 1847. Instead, the term "disturbance" was in vogue then. During a disturbance, Montriou (1847) revealed all magnetic elements disturbed in almost the same proportion, irrespective of whether the disturbance was small or large. Since this activity affected all the magnetic elements, it was reckoned that the presence of a polarity-varying disturbing magnetic pole had a terrestrial location different from that of the Earth's magnetic pole, which acquired or lost its magnetic property. The disturbing pole was defined to have caused initiation when $D$ was generally less eastward, $H$ marginally enhanced, $Z$ remained constant, $I$ decreased a little, and $F$ was a little more than normal. But, at the enhancement of disturbance intensity, $D$ increased easterly, $H$ decreased, $Z$ remained almost constant or slightly increased, $I$ increased, and $F$ rapidly decreased (Montriou, 1847). These indicators forced the observatory staff to deduce that the intensity of magnetic elements increased a little more than normally (the first phase of magnetic storms, storm sudden commencement
(SSC), as we know it today), then lost all of its intensity (main phase) and after a day or two came back to its original intensity (recovery phase).

The geographical location of the disturbed pole, whose effects were felt at Mumbai, was calculated to have declination $7^{\circ} 40^{\prime} \mathrm{W}$ and dip 2.01 above the horizon (Montriou, 1847). In fact, the observatory staff were not alone in fixing the geographical location of the disturbed pole. They had a strong advocate in Colonel Sabine, who, in his "Magnetic Disturbances", Part I, 1840-41, page 6 of the introduction, writes, "Suppose that this fact is proved at all the Stations where Magnetic Observations are made, it is probable, that like the Magnetic pole, there is one point on the Earth's surface from which the Magnets at all the Stations on the Earth are disturbed: the direction of this point, of course, being different for the different places of Observation. If the Disturbances which have occurred at the several Stations were reduced, according to the above form, each Station would furnish a direction; and these several directions will determine the Latitude and Longitude of the point of Disturbance, as well as its height (if any) from the surface of the Earth".

The magnetic disturbance, or the more common term these days, the magnetic storm, is a very complex phenomenon. It involves dynamic variations in a number of parameters right from the Sun to the Earth, and the space between these two entities. The first documented "magnetic storms" record 


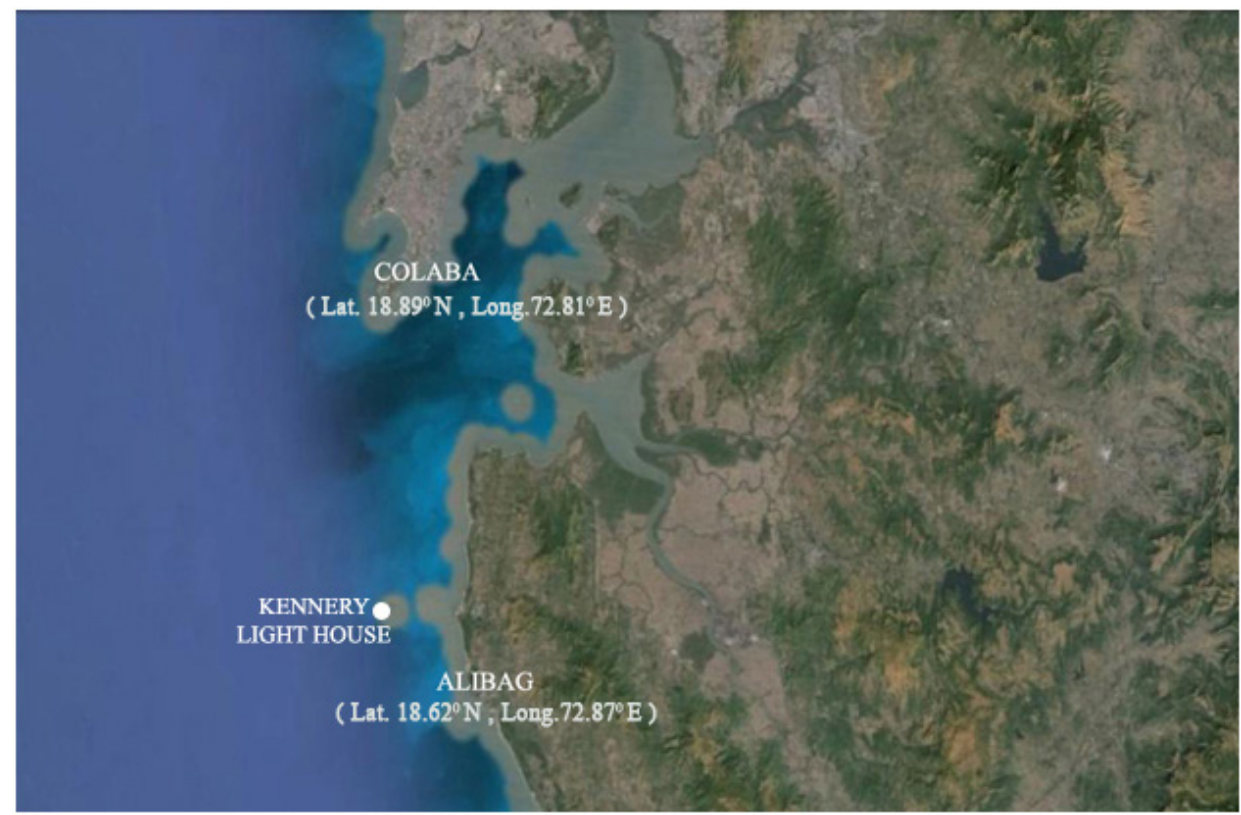

Figure 18. The geographical positions of Colaba and Alibag with respect to each other (source: Google Maps).
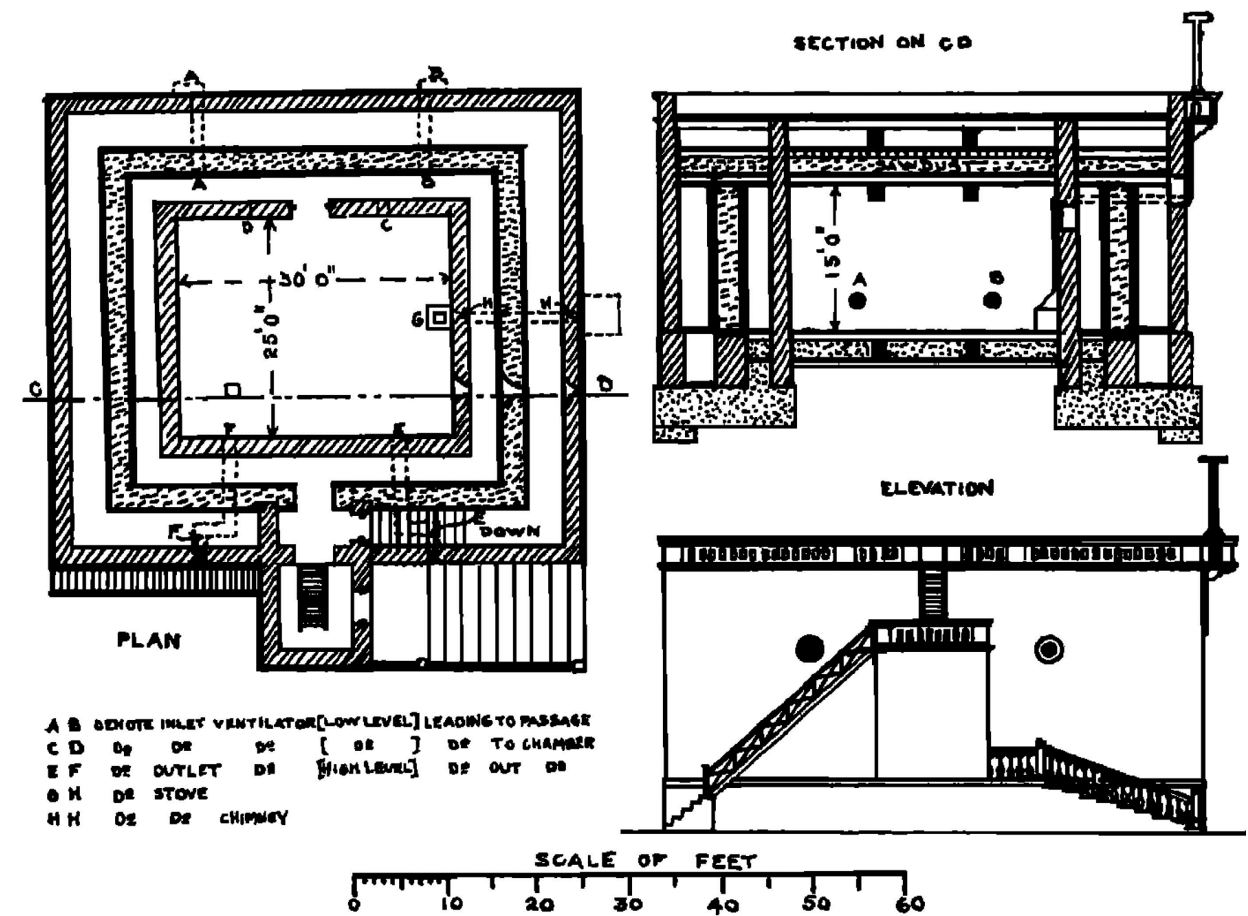

Figure 19. Plan for the overground magnetograph building at Alibag (Moos, 1912). This was the variometer room. The plan given on the left is that of the variometer room. The walls were separated by a distance of $3 \mathrm{ft}$. The thick black lines denote wooden planks between which sawdust was stuffed for uniform temperature. The walls were made from Porbunder sandstone and each and every block of this rock was personally tested by Moos to make sure the observatory was nonmagnetic in nature.

is attributed to Alexander von Humboldt (1808). Chapman $(1919,1935)$ and Birkeland $(1896,1913)$ used the term in different contexts, though the modern understanding of the term "magnetic storm" should be attributed to Moos (1910a, b). Moos compiled extensive and exhaustive data series from Colaba and Alibag observatories that helped him understand 


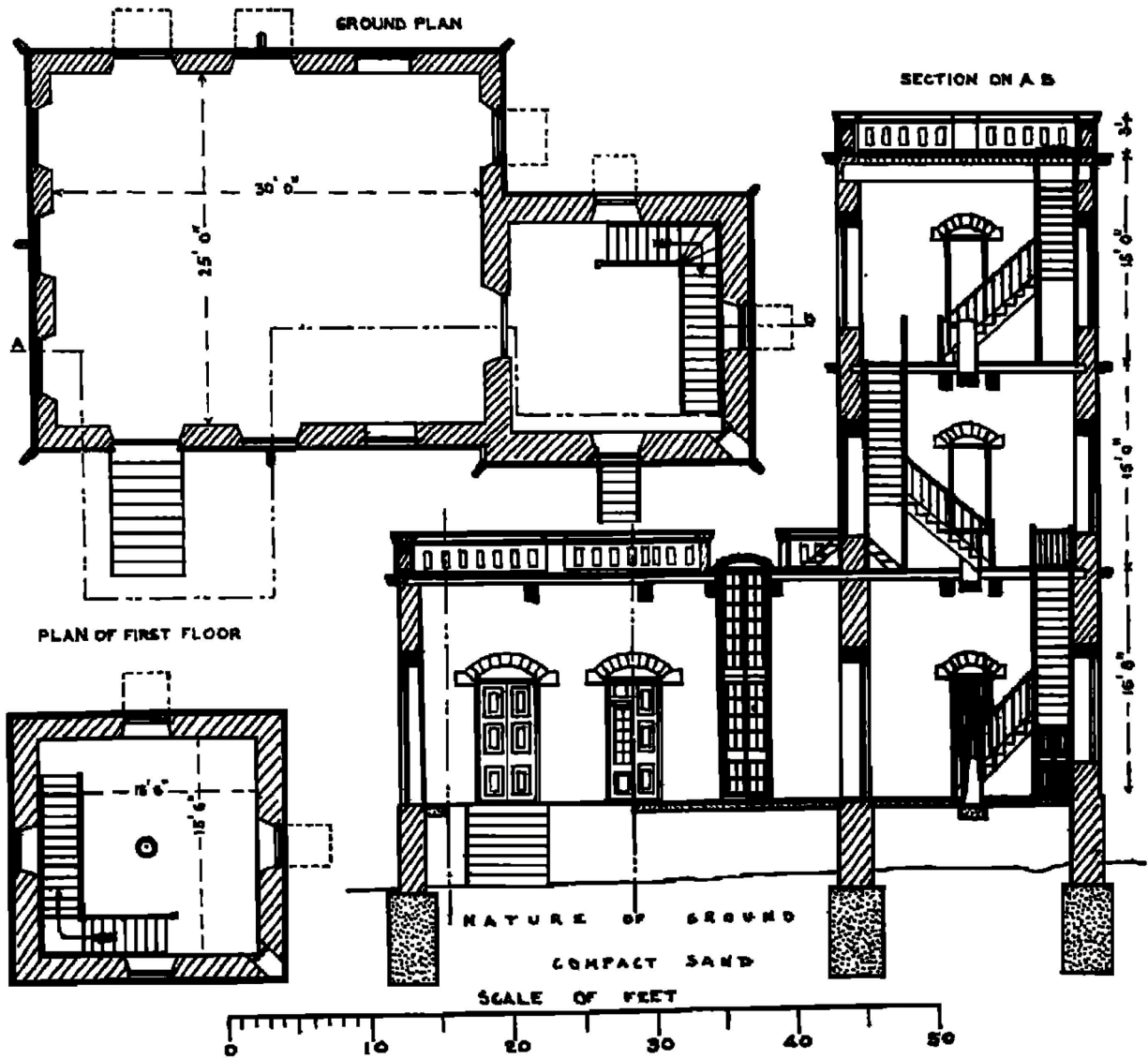

Figure 20. The plan for a magnetometer building that has a basement and two floors (Moos, 1912). This is also called a tower or absolute building.

the finer details of magnetic storms. Even Chapman applied Moos' methods to study features of moderate storms recorded at different geographic locations (Chapman and Bartels, 1940), helping him decipher their global spread and identifying Dst variation. The two most significant magnetic storms recorded and discussed by Moos $(1910 \mathrm{a}, \mathrm{b})$ were those of September 1859 and February 1872. Moos showed from a quadratic formula the dependence of changes in the absolute magnetic elements upon the sunspot cycle by representing the difference $(O-C)$ between the observed and computed values of magnetic elements $D, I, Z, H$, and $F$ for the period of accurate observations, 1888-1905, at Colaba (Bauer, 1918). Moos investigated disturbance daily variation in great detail (Unakar, 1936b) by employing the methodology of acquiring the difference between mean solar daily variation on disturbed and quiet days. He showed that disturbance daily variation depended on local time. Moos also contributed to identifying the lunar effect on geomagnetic recordings and tried to understand seismological repercussions for magnetic elements (Moos, 1910b). The meteorological phenomena affecting the magnetic readings were also deeply probed by Moos (1910b).
He chronicled the disturbance of the magnetic and meteorological instruments at Colaba Observatory during the earthquake of 12 June 1897 (Moos, 1910a). Moos (1910b) collected seismic data from 1889 to 1897 and 1889 to 1905 , respectively, from Milne and Colaba observatory seismographs. The analyses revealed that $47 \%$ of the earthquakes fell on magnetic calm days. He also explored the possibility of unraveling the interrelationship between magnetic and seismic activity, but found a sparse correlation.

\section{Moving Colaba Observatory to Alibag: the role played by Nanabhoy Moos}

Though the native population around Colaba Observatory was steadily rising by 1852 , it did not affect magnetic readings (Fergusson, 1859). To cater to an ever-increasing population, it was planned to install horse-driven tramways in Mumbai in 1864, but the contract to Stearns and Kitteredge was issued only in 1873 (Chopra, 2011). The route chosen was from Parel to Colaba (Fig. 1), on which the first trams ran, drawn by a group of six to eight horses (Dwivedi and Mehrotra, 1995). At the start of the tramway service in 1874 , 
Stearnes and Kitteredge had 900 horses in its stables. With an increasing population, it was decided to convert the horsedriven tramways into electric ones. However, this change had the capacity to vitiate magnetic recordings at Colaba.

\subsection{Moos and his efforts}

Moos reigned during the episode when the actual possibility of the electric tram service impeding magnetic recordings at Colaba was threatening to be a reality. He eloquently described the efforts he undertook, initially to stave off this crisis, and then to find an alternate solution (Moos, 1912):

Early in 1900 the city of Bombay finally decided to employ electricity as motive power for its street tram service. Magnetic work, hence, which had run uninterruptedly for over fifty years by then at the Bombay Observatory was thus threatened by the proposed introduction of the electric traction, and prompt action in the interests of the Observatory seemed essentially urgent. Efforts to find some "modus vivendi" which might allow this work to be continued at the Observatory without serious vitiation from the disturbing effects of the lines, having proved abortive an alternative seemed possible but to remove the magnetic work to some suitable site in the neighborhood. It became imperative under the circumstances to make provision without delay for the establishment of the new Observatory at some protected site elsewhere, which might allow comparative observations for a fairly long period to be made at the old and new sites before the conversion of the ordinary tram-lines into electric traction was completed, and enable, if possible, the continuity of the Bombay record to be preserved.

The necessary sanction and orders were graciously issued by Government and a suitable site, one least open to objection, from several recommended, was selected some eighteen miles away from Bombay. It was far away, enough to be beyond the disturbing effects of the electric lines in Bombay, but sufficiently near, presumably, to have similar magnetic conditions. The geographical position of Alibag also was otherwise favorable. There was no reasonable probability at least in the near future, of a railway service (eventually driven by electric motive power) extending southwards from the Bombay line along the coast through Alibag, or passing by it near enough to affect the magnetic work and complete the removal of the Observatory again to another site in a few decades.

The site was secured in 1902. The construction of the buildings, the description of which follows was completed in 1903, and comparative observations commenced in April, 1904. After securing an undisturbed duplicate record extending over a period of two years, the magnetic work at Colaba was stopped on 31st March, 1905, fortunately before the electric tram service was completed and had commenced its operations. Disturbed records at Colaba were subsequently also secured for a few days when the electric tram-lines were working in Bombay. The comparative results of absolute values of the three elements $H, D$, and $I$, at the two sites show that at Alibag $H$ stands lower by $510 \gamma$, $D$ (easterly) stands higher by $53^{\prime} .5$, and $I$ stands higher by $1^{\circ} 4^{\prime} 7^{\prime \prime}$ than at Colaba (Bombay), which are the finally adopted differences.

The variations of $H, D$ and $F$ were secured by a set of Watson's magnetographs at Alibag, and Kew type magnetographs at Colaba, and the results show, as anticipated, that the variation phenomena were precisely the same at the two sites, agreeing to within a $\gamma$ or two in the intensity variations, and $0^{\prime} .1$ in the declination variation.

\subsection{Alibag magnetic observatory}

Alibag Observatory is spread over 7 acres of land and is situated at lat. $18^{\circ} 38^{\prime} .3 \mathrm{~N}$ and lon. $72^{\circ} 52^{\prime} .4 \mathrm{E}$ (Fig. 18), bounded on three sides by roads and on the southwestern side by the sea. The then observatory consisted of the director's quarters, assistants' residence, an office and photographic room, apart from two buildings (Moos, 1912). The magnetometer building contained an office where eye-reading variometers were kept and absolute observations made. The magnetograph building (Fig. 19) housed two sets of variation instruments by Watson and Eschenhagen. Both buildings were constructed from nonmagnetic Porbunder sandstone brought from the Kathiawar region of Gujarat state. All the fittings were made either of copper or brass (Moos, 1912).

The magnetometer building (Fig. 20) had a basement and tower with two floors (Moos, 1912). The transit instrument (Fig. 21), along with the chronometer (Fig. 22), was used to determine local time. Magnetographs of Kew type were mounted in the basement room. The roof was constructed such that it allowed sightings for star observations. These magnetographs were in use at Colaba for almost 35 years (Moos, 1912), albeit as simple eye-reading variometers. The second floor tower room housed observatory standard instruments - magnetometer no. 7, by Cooke, Schulze's inductor, and a dip circle (Moos, 1912). On the first floor, auxiliary observations of $H$ and $D$ were taken with magnetometer no. 3, designed by the Cambridge Scientific Instrument Company. On the ground floor, magnetometer no. 137, by Dover Charlton (Fig. 23), was used for deflection experiments. These served as a check on the deflection experiments of magnetographs for standardizing curves (Moos, 1912). Kennery lighthouse (Fig. 18), like Colaba, provided a ref- 


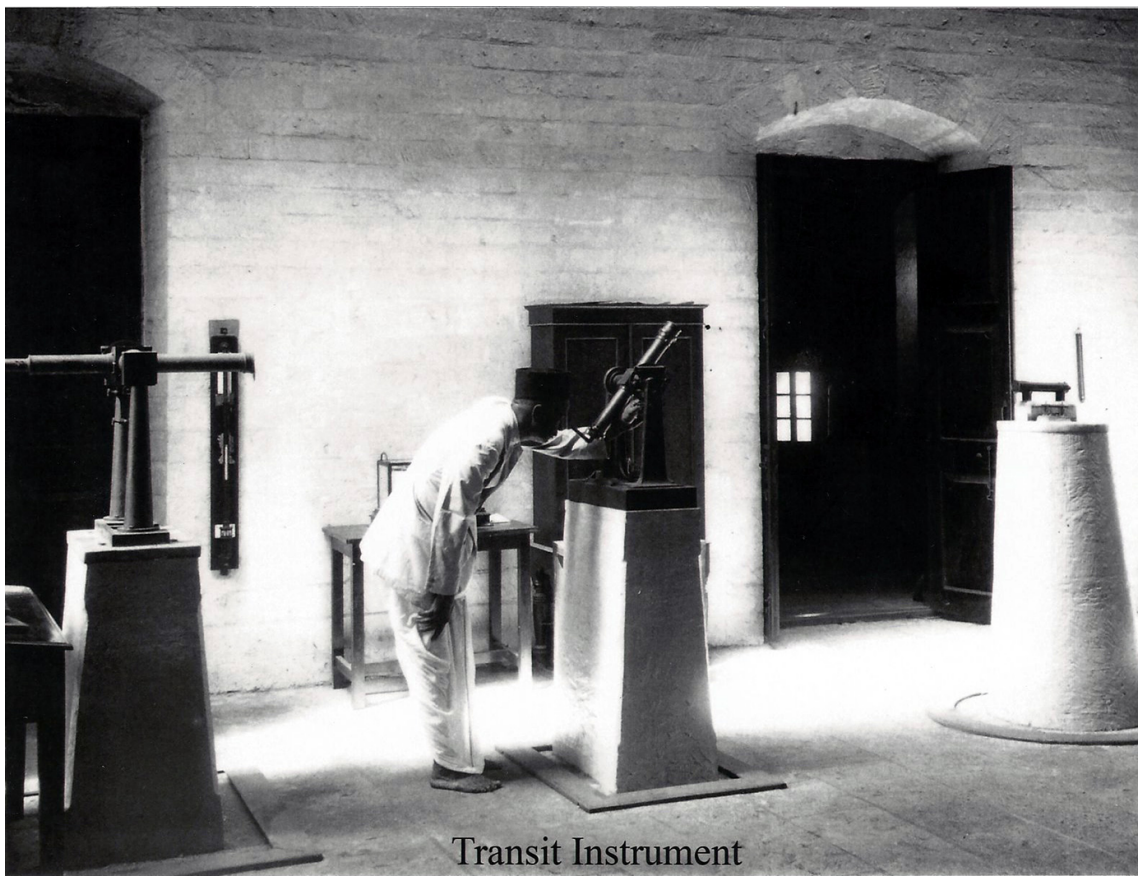

Figure 21. An observer busy at observing the transit of stars to provide accurate time at Alibag. The chronometer and pendulum were used for correct time. This accurate time was conveyed to the public by ringing a bell at 21:00. The ringing of the bell continued till the 1980s. Later on, a siren was blown at 10:00 on request from local authorities. These days digital displays serve this function (courtesy of Colaba-Alibag Observatory).

erence mark for azimuth observations to Alibag Observatory as well (Moos, 1912).

The recording variation instruments were mounted in an overground magnetograph building (Fig. 19; Moos, 1912). The routine work (Moos, 1912) at Alibag Observatory comprised the following: Cooke's magnetometer, kept on the second floor of the tower, and the Cambridge Scientific Instrument Company's magnetometer no. 3, placed on the first floor, were, respectively, used to derive absolute $H$ every Monday and Thursday. $D$ was derived every Thursday by both these instruments. Except for Sundays, $I$ was derived by the inductor on all other days on the second floor, and also by the dip circle every Saturday (Moos, 1912). Eye observations of $D, H, Z$ of the variometer and magnetograph were of both Kew (Fig. 24) and Eschenhagen make; thermometer readings of variation instruments and thermographs in the magnetograph room were taken daily, including Sundays, at 06:00, 10:00, 14:00, 16:00 and 22:00 (Moos, 1912). Deflection experiments were carried out with the magnet of magnetometer no. 3 , the moment of which was termed the "deflector". These were made at $100 \mathrm{~cm}$ distance on $H$ variometers, and at $75 \mathrm{~cm}$ distance on $Z$ variometers, once every fortnight. Similar deflection experiments, with the magnet of magnetometer no. 137 as a deflector, were made once a month on the magnetographs, as a check on fortnightly work, and corresponding deflection experiments at the same distances were also made every month by the same deflector upon a magnet appropriately suspended over the pillar on the ground floor room of the tower (Moos, 1912). Transit observations of stars for the determination of time were made regularly twice a week (Moos, 1912).

All other work, including the hourly tabulation of magnetograms, reduction of observations, determination of diurnal variations and daily means (absolute values) of all days, also of quiet days selected by the Astronomer Royal and by the International Commission of Terrestrial Magnetism, and of quiet days selected locally, was carried out at Colaba (Moos, 1912). Even after moving the magnetic observatory to Alibag, Colaba continued to function, carrying out analyses and publication of data in their varied forms.

\section{Conclusions}

Geomagnetic research during the inception of Colaba Observatory greatly differed from that of today. The instruments were robust, observations incomplete and basic understanding of the geomagnetic phenomena in its infancy. Even then it was an exciting time of discovery and inventiveness. The personnel took great care and efforts to record data in the best possible manner. Most of the geomagnetic research in the late 19th century was carried out in institutions dedicated to meteorological phenomena. The complexities of the two were juxtaposed and efforts made to understand their interrelationship. The Colaba-Alibag magnetic data form a long 


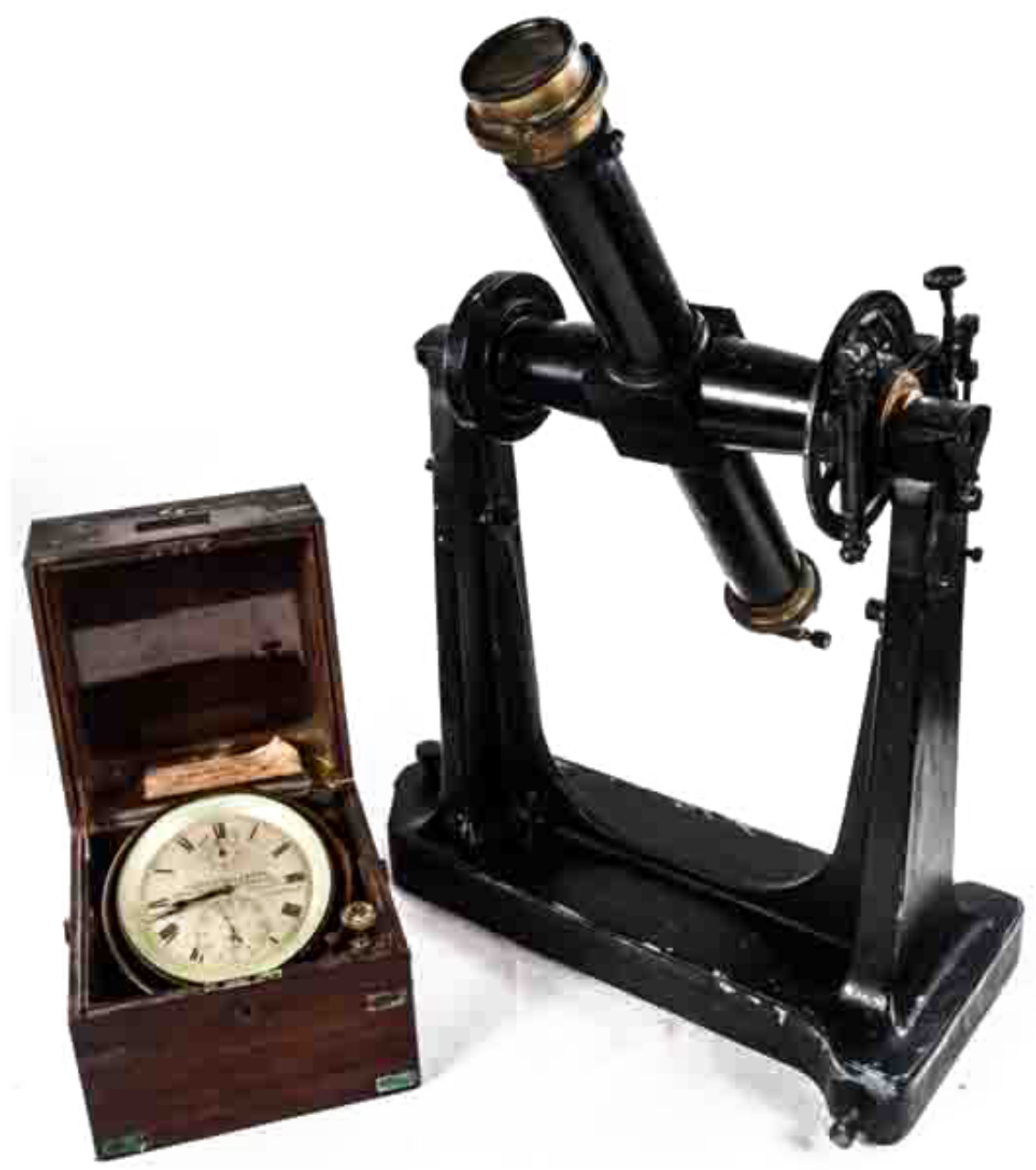

Figure 22. Transit telescope and chronometer (courtesy of Colaba-Alibag Observatory).

series of over 174 years gleaned from difficult conditions by the finest men of science through the gift of their observational and theoretical faculties.

Observatories set up during the colonial days have amassed copious data contributing immensely towards understanding global dynamics of magnetic processes operative in the domain encompassing the Earth, space and the Sun. In those days space's impact on terrestrial magnetic recordings was not appreciated. The magnetic storm vitiated most of the magnetic elements and these were attributed to dynamical changes occurring along a "disturbing point" whose latitude and longitudinal position were routinely calculated at many places across the globe. While the stalwarts of the time were thus looking to the Earth, Moos was however exploring the atmosphere. He rightly attributed the origin of magnetic storms to activities occurring in the heliospheric realm. The efforts of Moos to reconcile diverse natural processes operating in geomagnetic, seismic and meteorological domains need to be lauded for their sheer audacity and expansive sweep. He was definitely ahead of his times and the likes of Chapman and Mayaud had no hesitation in acknowledging his contribution to geomagnetic research. The immaculate and zealous preparations he undertook to move Colaba Observatory to Alibag are worth emulating even now. He personally tested Porbunder sandstone used in building the Alibag magnetic observatory to ensure its nonmagnetic character. His analytical skill and ability to comprehend hidden signatures in data are evident in the two volumes that he compiled from Colaba data series. Those are truly the magnum opus and need to be studied closely.

Colaba Observatory, like many others, gained from Gauss' invention of the differential instrument in the 1830s and from the development of photographic self-recording instruments in the 1840s. These developments nurtured and sustained the global observatory network, enabling one to record geomagnetic data as accurately as possible. With the onset of digital recording, the instruments once operational at Colaba and Alibag are no longer in use. However, with the passage of 


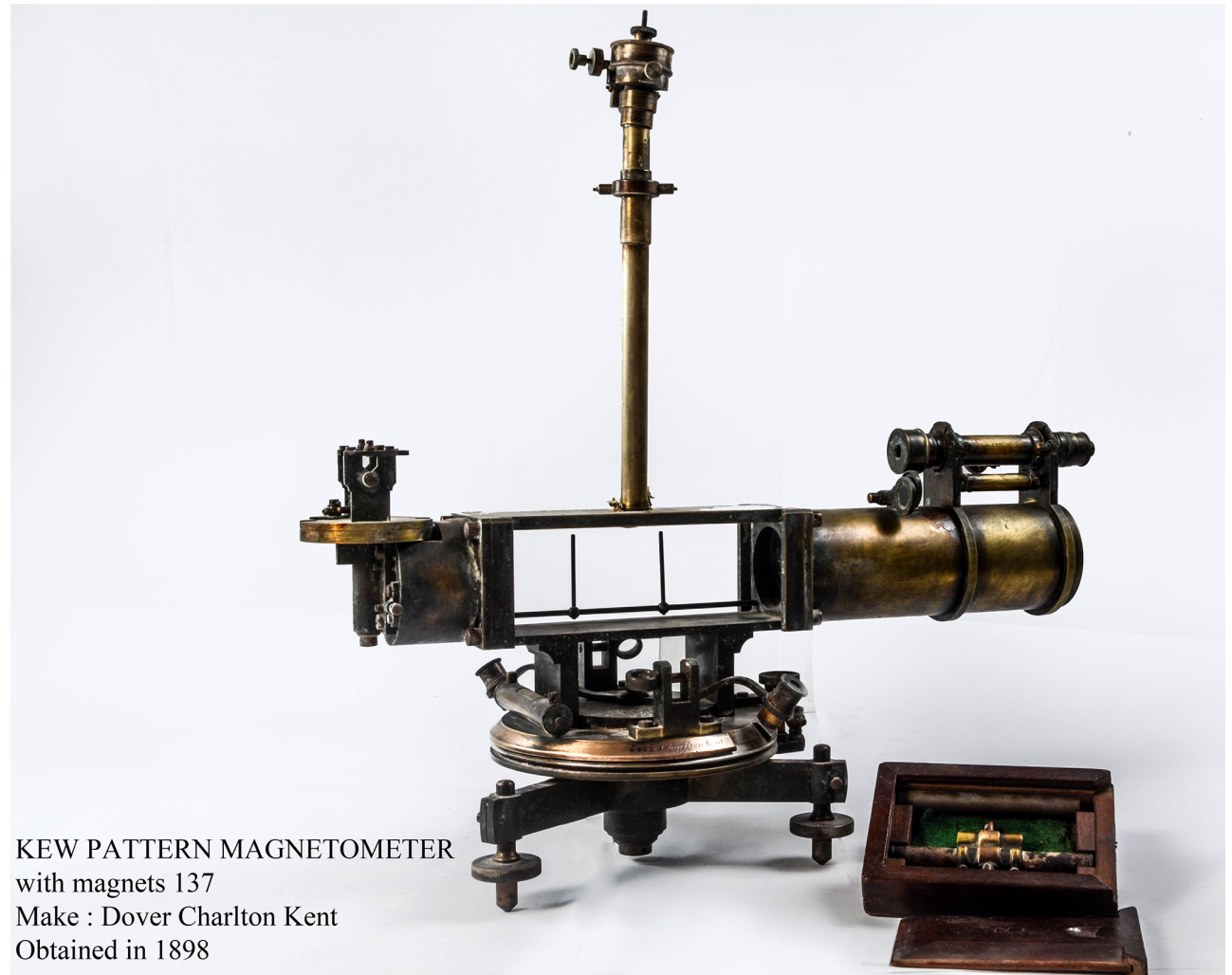

Figure 23. This magnetometer was used for deflection experiments (courtesy of Colaba-Alibag Observatory).

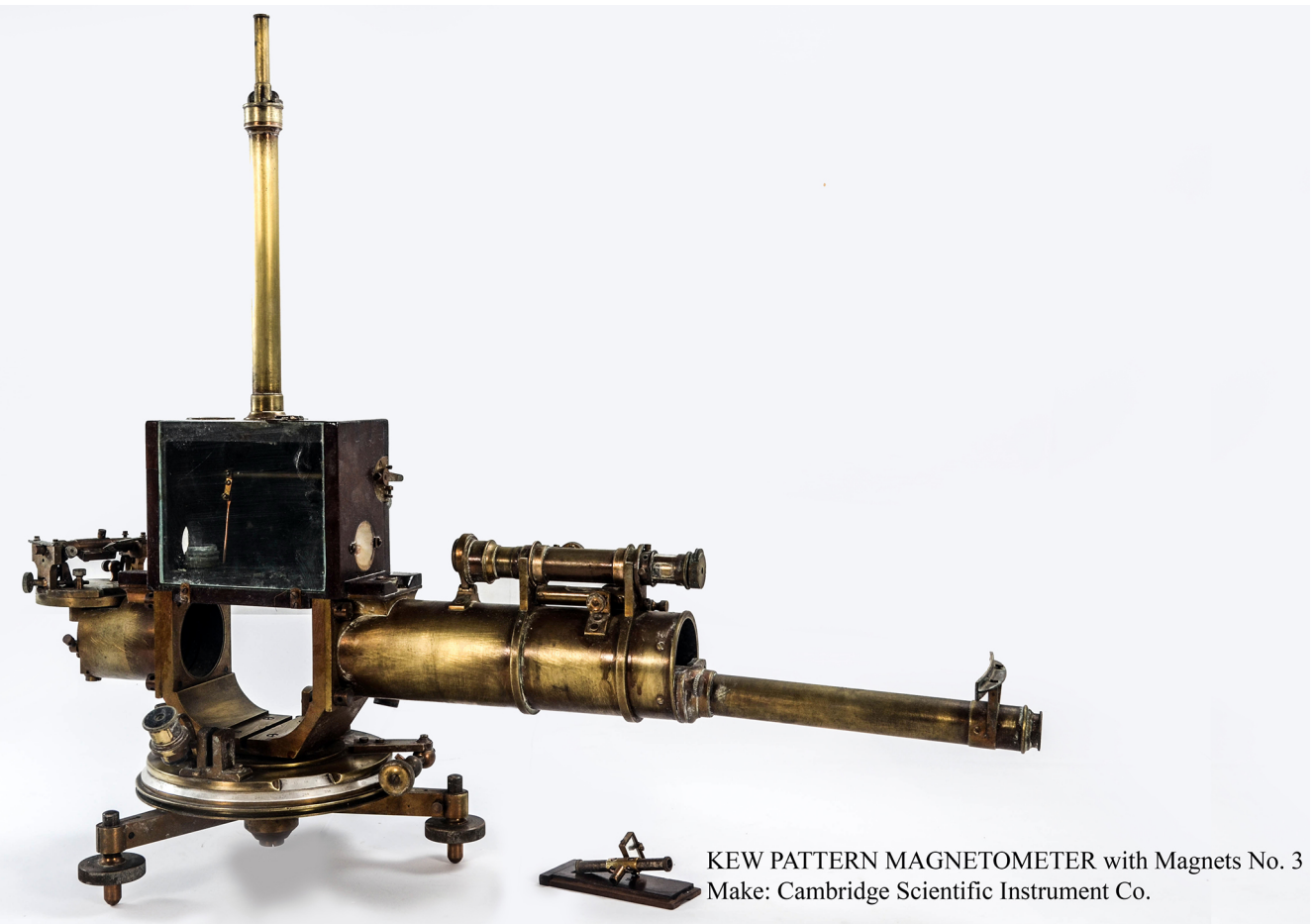

Figure 24. Kew pattern magnetometer with magnets no. 3 (courtesy of Colaba-Alibag Observatory). 
time, they have acquired a rich vintage quality. Their preservation should be at the top of the agenda. The instruments from Colaba have been archived at Alibag, the premier magnetic observatory of India.

Acknowledgements. The director of IIG, D. S. Ramesh, is thanked for permission to publish this article and for his constant support and encouragement. A. T. Deshmukh is thanked for valuable inputs on the old instruments. Nandini Nagarajan and another anonymous referee, along with the topical editor Kusumita Arora, are thanked for suggestions and encouragement that immensely enhanced the quality of this article.

Edited by: K. Arora

Reviewed by: N. Nagarajan and one anonymous referee

\section{References}

Baggot, J.: The myth of Michael Faraday, New Sci., 1787, 43-46, 1991.

Bauer, L. A.: Halley's earliest equal variation chart, J. Geophys. Res., 1, 28-31, 1896, reproduced in History of Geophysics, Hist. Geophys., vol. 4, edited by: Gillmor, S., AGU, Washington, DC, 2-5, 1990.

Bauer, L. A.: Magnetic results of Halley's expedition, 1698-1700, J. Geophys. Res., 18, 113-126, 1913, reproduced in History of Geophysics, Hist. Geophys., vol. 4, edited by: Gillmor, S., AGU, Washington DC, 11-21, 1990.

Bauer, L. A.: Relation between the secular variation of the Earth's magnetism and solar activity, Terrestrial Magnetism Atmospheric Electricity v. XXIII March, No. 1, 1918.

Bhardwaj, S. K.: Equatorial and low latitude geomagnetic field oscillations in the Indian region, J. Ind. Geophys. Union., 13, 107$120,2009$.

Bhardwaj, S. K. and Rangarajan, G. K.: A model for solar quiet day variation at low latitude from past observations using singular spectrum analysis, Proc. Indian Acad. Sci. (Earth Planet. Sci.), 107, 217-224, 1998.

Bhardwaj, S. K. and Rao, S. P. B. V.: Secular trend of geomagnetic elements in the Indian region, Earth Planet. Space, 65, 15151523, 2013.

Birkeland, K.: Cathode rays under the influence of strong magnetic forces, Electrical Review, 968, 1896.

Birkeland, K.: The Norwegian Aurora Polaris Expedition, 19021903, Vol. 1, Aschehpug and Co., Christiania, First Section, 1908, Section 2, 1913.

Broun, J. A.: Observations of magnetic declination made at Trivandrum and Augustia Malley in the observatory of His Highness the Maharajah of Travancore GCSI in the years 1852-1869, Henry S King and Co., London, 1874.

Cawood, J.: The magnetic crusade: Science and politics in early Victorian Britain, Isis, 70, 493-519, 1979.

Chambers, C.: Report of magnetical and meteorological observations from 1879-1882, Bombay, Central Government Press, 1888.

Chapman, S.: An outline of a theory of magnetic storms, Proc. Roy. Soc. London A, 95, 61-83, 1919.
Chapman, S.: The electric current systems of magnetic storms, Terrest. Magnetism Atmospheric Elec., 40, 349-370, 1935.

Chapman, S. and Bartels, J.: Geomagnetism, Vol.1, Oxford University Press, New York, 1940.

Chopra, P.: A joint enterprise: Indian elites and the making of British Bombay, University of Minnesota press, 2011.

Crichton, M. A.: Chapters in the history of terrestrial magnetism, (I) on the directive property of a magnet in the Earth's field and the origin of the nautical compass, Terr. Magn. Atmosph. Electr., 37, 105-146, 1932.

Crichton, M. A.: Chapters in the history of terrestrial magnetism, III, the discovery of the magnetic inclination, J. Geophys. Res., 44, 77-80, 1939.

Da'cunha, J.: Origin of Bombay, The Royal Asiatic Society, Bombay, 1900.

Dwivedi, S. and Mehrotra, R.: Bombay: the cities within, India book house, 1995.

Fergusson, E. F. T.: Report of magnetical and meteorological observations from January to December 1859 at Bombay, Volume 1, 1859.

Gauss, C. F.: The intensity of the earth's magnetic force reduced to absolute measurement, Royal Scientific Society, v.8, 3-44 (The treatise "Intensitas vis magneticae terrestris ad mensuram absolutam revocata" was read by Gauss at the Goettingen Gesellschaft der Wissenschaften (Royal Scientific Society) on 15 December 1832, and printed in Volume 8 of the treatises of this society, 3-44, 1832.

Gauss, C. F.: Allgemeine theorie des Erdmagnetismus, in Resultate aus den Beobachtungen des Magnetischen Verin im Jahie, 1838 (reprinted in Werke, Band 5, 121-193, Koniglichen Gessellschaft der Wissenschaften, Göttingen, 1877), 1839.

Gauss, C. F. and Weber, W.: Remarks on the construction of magnetic observatories and the instruments which they should contain, Annals of Electricity, 3, 92-108, Translated from the German edition of $1833,1839$.

Gilbert, W.: De Magnet, translation by: Motley, T., Dover Publication, New York, 0-486-26761-X, 1958.

Kamath, M. V.: Tides of time: history of Mumbai port, Mumbai Port Trust, 2000.

Malabari, P. B. M.: Bombay in the making (1661-1726), T. Fisher Unwin London, Adelphi Terrace Leipsic, Inselstrasse 20, 1910.

Malin, S. R. C. and Bullard, E.: The direction of the Earth's magnetic field at London, 1570-1975, Philos. Trans. R. Soc. London, 299, 357-423, 1981.

Maxwell, J. C.: A treatise on electricity and magnetism, Macmillan and Co. London, 1873.

Montriou, C. W.: Report of magnetical and meteorological observations from January to December 1847 at Bombay, Volume 1, 1847.

Montriou, C. W.: Report of magnetical and meteorological observatory, Bombay made by East India Company's observatory, Bombay in the year 1848, 1851 .

Moos, N. A. F.: Alibag magnetic observatory, Terr. Magnet. Atmos. Electr., 17, 173-240, doi:10.1029/TE017i004p00233, 1912.

Moos, N. A. F.: Magnetic observations made at the Government observatory, Bombay, for the period 1846 to 1905 and their discussion, Part I: Magnetic data and instruments, Government Central Press, Bombay, 1910a. 
Moos, N. A. F.: Magnetic observations made at the Government observatory, Bombay, for the period 1846 to 1905 and their discussion, Part II: the phenomenon and its description Government Central Press, Bombay, 1910b.

Multhauf, R. P. and Good, G.: A Brief History of Geomagnetism and A Catalog of the Collections of the National Museum of American History, Smithsonian Institution Press Washington, DC, 1987.

Orlebar, A. B.: Observations made at the magnetical and meteorological observatory, Bombay from April to December 1845, American Mission Press, 1846.

Riddell, C. J. B.: Magnetical Instructions for the Use of Portable Instruments Adapted for Magnetical Surveys and Portable Observatories, 1844.

Robinson, G. T., Chambers, C., and Chambers, F.: Magnetical and meteorological observations made at Government observatory, Bombay in the years 1865 to 1870 . Education Society Press, Byculla, Bombay, 1872.
Shamos, M. H.: Great Experiments in Physics, Henry Holt, New York, 370 pp., 1959.

Smith, J. A.: Precursors to Peregrinus: The early history of magnetism and the mariner's compass in Europe, J. Medieval History, 18, 21-74, doi:10.1016/0304-4181(92)90016-R, 1992.

Unakar, M. V.: Dr. N. A. F. Moos. Obituary, Current Sci., 4, 862 864, 1936a.

Unakar, M. V.: Dr. Nanabhai Ardesher Framji Moos, 1859-1936, Terr. Magn. Atmos. Electr., 41, 397-398, doi:10.1029/TE041i004p00397, 1936b.

von Humboldt, A.: Annalen der Physik, 29, 425-429, 1808.

Williams, L. P.: André-Marie Ampère, Sci. Am., 260, 90-97, 1989. 